\title{
Evaluation of $\mathrm{SO}_{2}, \mathrm{SO}_{4}^{2-}$ and an updated $\mathrm{SO}_{2}$ dry deposition parameterization in UKESM1
}

Catherine Hardacre ${ }^{1}$, Jane P. Mulcahy ${ }^{1}$, Richard Pope ${ }^{2,3}$, Colin G. Jones ${ }^{3}$, Steven T. Rumbold ${ }^{3}$, Can Li $^{4,5}$, and Steven T. Turnock ${ }^{1,6}$

${ }^{1}$ Met Office, Exeter, EX1 3PB, UK

${ }^{2}$ School Earth and Environment, University of Leeds, Leeds, UK

${ }^{3}$ National Centre for Atmospheric Science, University of Leeds, Leeds, UK

${ }^{4}$ NASA Goddard Space Flight Center, Greenbelt, MD 20771, USA

${ }^{5}$ Earth System Science Interdisciplinary Center, University of Maryland, College Park, MD 20742, USA

${ }^{6}$ University of Leeds Met Office Strategic (LUMOS) Research Group, School of Earth and Environment, University of Leeds, UK

Correspondence: Catherine Hardacre (catherine.hardacre@ metoffice.gov.uk)

Abstract. In this study we evaluate simulated surface $\mathrm{SO}_{2}$ and sulphate $\left(\mathrm{SO}_{4}^{2-}\right)$ concentrations from the United Kingdom Earth System Model (UKESM1) against observations from ground based measurement networks in the USA and Europe for the period 1987 to 2014. We find that UKESM1 captures the historical trend for decreasing concentrations of atmospheric $\mathrm{SO}_{2}$ and $\mathrm{SO}_{4}^{2-}$ in both Europe and the USA over the period 1987 to 2014. However, in the polluted regions of the eastern

5 USA and Europe, UKESM1 over-predicts surface $\mathrm{SO}_{2}$ concentrations by a factor of 3, while under-predicting surface $\mathrm{SO}_{4}^{2-}$ concentrations by $25-35 \%$. In the cleaner western USA, the model over-predicts both surface $\mathrm{SO}_{2}$ and $\mathrm{SO}_{4}^{2-}$ concentrations by a factor of 12 and 1.5 respectively. We find that UKESM1's bias in surface $\mathrm{SO}_{2}$ and $\mathrm{SO}_{4}^{2-}$ concentrations is variable according to region and season. We also evaluate UKESM1 against total column $\mathrm{SO}_{2}$ from the Ozone Monitoring Instrument (OMI) using an updated data product. This comparison provides information about the model's global performance, finding that UKESM1 over predicts total column $\mathrm{SO}_{2}$ over much of the globe, including the large source regions of India, China, the USA and Europe as well as over outflow regions. Finally, we assess the impact of a more realistic treatment of the model's $\mathrm{SO}_{2}$ dry deposition parameterization. This change increases $\mathrm{SO}_{2}$ dry deposition to the land and ocean surfaces, thus reducing the atmospheric loading of $\mathrm{SO}_{2}$ and $\mathrm{SO}_{4}^{2-}$. In comparison with the ground-based and satellite observations, we find that the modified parameterization reduces the model's over prediction of surface $\mathrm{SO}_{2}$ concentrations and total column $\mathrm{SO}_{2}$. Relative to the ground-based observations the simulated surface $\mathrm{SO}_{4}^{2-}$ concentrations are also reduced, while the simulated $\mathrm{SO}_{2}$ dry deposition fluxes increase. 


\section{Introduction}

Anthropogenic sulphur dioxide $\left(\mathrm{SO}_{2}\right)$ emissions have been the main driver of the historical aerosol effective radiative forcing (ERF) since the mid 20th century (Boucher et al., 2013). $\mathrm{SO}_{2}$ is emitted into the atmosphere from a number of anthropogenic (and natural) sources and once in the atmosphere $\mathrm{SO}_{2}$ can be oxidised to form sulphate $\left(\mathrm{SO}_{4}^{2-}\right)$ aerosol, which plays a key role in both acid deposition, atmospheric aerosol loading and cloud properties, thereby directly influencing the Earth's radiative balance. For Earth system models (ESMs) to have a good representation of the historical climate and thereby give us confidence in their future projections, it is extremely important that they can capture the sulphur cycle. The UK's Earth system model (UKESM1), in common with other ESMs, has a cold bias in the mid 20th century which looks to be associated with an excessively negative aerosol ERF (Sellar et al., 2019; Seland et al., 2020). A key component of the analysis and development of UKESM1 focuses on the model's sulphur cycle and its link to historical aerosol forcing. Mulcahy et al. (2020) conducted an in-depth evaluation of the aerosol species in UKESM1 and its physical model component, HadGEM3-GC3.1, including $\mathrm{SO}_{4}^{2-}$ and uncovered some interesting differences in the sulphur budget between these two models including differences in the $\mathrm{SO}_{2}$ lifetimes and oxidant loading. We aim to extend their work by conducting a detailed evaluation of $\mathrm{SO}_{2}$ and by probing deeper into the process level uncertainty of the sulphur cycle.

Sources of $\mathrm{SO}_{2}$ include industry, energy, land-based transport shipping, volcanoes, biomass burning and marine di-methyl sulphide (DMS) (Feng et al., 2020; Fioletov et al., 2016; Liu et al., 2018; Janssens-Maenhout et al., 2015; Crippa et al., 2018). Total global emissions of $\mathrm{SO}_{2}$ increased to a peak value of approximately $180 \mathrm{Tg} \mathrm{y}^{-1}$ in the $1970 \mathrm{~s}$, but following emission reduction policies to improve air quality and reduce acid deposition that were implemented in the 1980s (Hoesly et al., 2018), total global emissions had decreased to approximately $120 \mathrm{Tg}^{-1}$ by 2015 (Aas et al., 2019). This trend is captured in global models, but there is substantial temporal variation at the regional scale (Aas et al., 2019). Legislation has driven reductions in $\mathrm{SO}_{2}$ emissions and subsequently $\mathrm{SO}_{4}^{2-}$ aerosol across Europe (Torseth et al., 2012) and North America (Sickles II and Shadwick, 2015; Holland et al., 1998). In these regions reductions in $\mathrm{SO}_{2}$ emissions have had important environmental and health benefits as well as climate impacts. Turnock et al. (2015) found that between 1970 and 2010 surface $\mathrm{SO}_{4}^{2-}$ aerosol reduced by about $70 \%$ in the observations and also in the simulations. For the same period, top of atmosphere (TOA) aerosol radiative forcing over this region increased by $>3 \mathrm{~W} \mathrm{~m} \mathrm{~m}^{-2}$ in response to these changes in anthropogenic emissions. Similarly Leibensperger et al. (2012) reported that over the USA aerosol raditive forcing decreased by $1.0 \mathrm{~W} \mathrm{~m} \mathrm{~m}^{-2}$ in the period from 1990 to 2010. Emission reduction policies in China have been implemented since 2013, which has reduced anthropogenic $\mathrm{SO}_{2}$ emissions (Aas et al., 2019; Zheng et al., 2018; Hoesly et al., 2018; Liu et al., 2018; Krotkov et al., 2016), and subsequently driven decreases in aerosol optical depth (AOD) (Zhao et al., 2017). However, $\mathrm{SO}_{2}$ emissions from India continue to increase (Aas et al., 2019; Liu et al., 2018; Krotkov et al., 2016). 
by the emissions (sources) to the atmosphere and the loss processes, which are oxidation to $\mathrm{SO}_{4}^{2-}$, dry deposition and wet deposition. Global scale $\mathrm{SO}_{2}$ emissions are represented in ESMs using emission inventories such as HTAP (Janssens-Maenhout et al., 2015), OMI-HTAP (Liu et al., 2018), EDGAR (Crippa et al., 2018) and CMIP6 (Feng et al., 2020), the latter being developed for use by models participating in the CMIP6 project (Eyring et al., 2016). Although uncertainty in $\mathrm{SO}_{2}$ emissions is relatively low (Hoesly et al., 2018), in bottom up inventories such as HTAP and EDGAR there may be uncertainty in the emission and activity factors, in the conversion from country scale to grid scale, and the input data may be incomplete or subject to rapidly changing economic and/or policy conditions (Janssens-Maenhout et al., 2015). In satellite derived data sets there is uncertainty associated with the retrieval methods and the signal to noise ratio, which can make smaller sources and background concentrations more difficult to detect (Fioletov et al., 2016). Yang et al. (2019) have also found that injection height is a larger source of uncertainty in model representation of $\mathrm{SO}_{2}$ emissions than inventory uncertainty, affecting surface concentrations by $70-130 \%$ depending on sector and region, compared with $8-14 \%$ from inventory uncertainty. The impact of injection height in UKESM1 was demonstrated by Mulcahy et al. (2020) who found that emitting $\mathrm{SO}_{2}$ higher in to the atmosphere, rather than in to the lowest model level increased the burden from $0.53 \mathrm{Tg}$ to $0.61 \mathrm{Tg}$ and the lifetime from 2.08 to 2.21 days, although $\mathrm{SO}_{4}^{2-}$ was not significantly affected.

Anthropogenic emissions of $\mathrm{SO}_{2}$ are generally from point sources such as power stations or smelters. Once emitted $\mathrm{SO}_{2}$ has a lifetime of approximately two days, although this can vary from $15 \mathrm{~h}$ to $65 \mathrm{~h}$ in summer and winter, respectively (Lee et al., 2011). The relatively short lifetime of $\mathrm{SO}_{2}$ means that much of the loss via oxidation and deposition occurs locally, with the ratios of the different loss processes highly dependant on the surface type, soil $\mathrm{pH}$, solar radiation level, near-surface relative humidity and, in particular, whether the underlying surface is wet or dry, with deposition increasing significantly for a wet surface. $\mathrm{SO}_{2}$ loss near sources and the impact of environmental conditions on these processes have been investigated in a number of studies.

Wys et al. (1978) calculated diurnal averaged deposition of emitted $\mathrm{SO}_{2}$ onto an agricultural field of $35 \%$ within $300 \mathrm{~km}$ of the emission source, with daytime deposition significantly higher than at night. The same study found that $15 \%$ of emitted $\mathrm{SO}_{2}$ was dry deposited onto an arid desert surface within $300 \mathrm{~km}$ of the source. Studies over Europe indicate similar rates of deposition and sensitivity to surface type. For example, using flight observations off the East coast of the UK Smith and Jeffrey (1975), estimated $50 \%$ of the $\mathrm{SO}_{2}$ emitted from UK sources was removed from the atmosphere, or converted to $\mathrm{SO}_{4}^{2-}$ by the time it was observed in air parcels over the North Sea. This amounts to a loss or conversion of $50 \%$ emitted $\mathrm{SO}_{2}$ within 200-300 km of the emission source. Smith and Jeffrey (1975) further partitioned this loss into 30-35\% due to dry deposition and $10-15 \%$ oxidation to $\mathrm{SO}_{4}^{2-}$, with wet deposition making only a minor contribution to the total loss. Similar rates of $\mathrm{SO}_{2}$ loss have been observed in a number of other observational studies of dry deposition (e.g., Payrissat and Beilke, 1975; Garland and Branson, 1977; Fowler, 1978; Erisman and Baldocchi, 1994). Studies analysing $\mathrm{SO}_{2}$ dispersion around U.S. power stations found that fractional oxidation rates to $\mathrm{SO}_{4}^{2-}$ are sensitive to the amount of solar radiation, with rates ranging from a winter low of $1 \times 10^{-3} \mathrm{~h}^{-1}$ to a summer high of $1.5 \times 10^{-2} \mathrm{~h}^{-1}$ (Altshuller, 1979; Meagher et al., 1983). Representing the $\mathrm{SO}_{2}$ 
loss processes is challenging for ESMs because $200-300 \mathrm{~km}$ is represented by $1-2$ grid cells, meaning that deposition and oxidation are parameterized on the model grid scale and may not capture temporal and spatial variation. In addition there is uncertainty associated with the oxidation and deposition processes.

In the atmosphere $\mathrm{SO}_{2}$ can be oxidised in the gas phase by hydroxyl $(\mathrm{OH})$ radicals and in the aqueous phase by reactions in cloud and rain water involving hydrogen peroxide $\left(\mathrm{H}_{2} \mathrm{O}_{2}\right)$, ozone $\left(\mathrm{O}_{3}\right), \mathrm{O}_{2}$ catalyzed by transition metal ions, and other oxidants to form $\mathrm{SO}_{4}^{2-}$, see Turnock et al. (2019) and references within. The oxidation chemistry is necessarily simplified in many models due to the computational cost of detailed chemistry schemes, but studies have shown that oxidant levels can impact the lifetime of aerosol precursor species and ultimately global radiative forcing (Mulcahy et al., 2020; Karset et al., 2018). Uncertainty in aerosol radiative forcing also results from different values of cloud water $\mathrm{pH}$, which alters $\mathrm{SO}_{4}^{2-}$ formation by changing the rate of aqueous phase oxidation of $\mathrm{SO}_{2}$ by ozone (Turnock et al., 2019). Observations have shown that cloud pH is both temporally and spatially variable (Aleksic et al., 2009; Murray et al., 2013; Schwab et al., 2016; Li et al., 2017), although measurements are very sparse. Typically, this variation is not accounted for in global chemistry climate models, including UKESM1 and its predecessor HadGEM3-GC3.1, both of which use a temporally and spatially constant cloud $\mathrm{pH}$ of 5.0. Turnock et al. (2019) found that increasing the cloud $\mathrm{pH}$ by 1.0 in HadGEM3-GC3.1 reduced the total $\mathrm{SO}_{2}$ column by up to 50\% over Europe, North America, and East Asia for 1970-1974 and 2005-2009. The impact on $\mathrm{SO}_{4}^{2-}$ was variable due to the different $\mathrm{SO}_{2}$ loadings over the different regions and in the different time periods. Overall aerosol radiative forcings varied by up to $4 \mathrm{~W} \mathrm{~m}^{-2}$, with larger changes in some regions depending on whether cloud water $\mathrm{pH}$ was assumed to have increased or decreased over recent decades.

Loss of $\mathrm{SO}_{2}$ and $\mathrm{SO}_{4}^{2-}$ to the Earth's surface by deposition can be through dry or wet processes. Dry deposition describes the removal of a gas or particle through direct contact of air with the Earth's surface and wet deposition describes the incorporation of gases or particles into rain droplets or snow crystals and their subsequent removal through precipitation. Globally dry deposition removes around $45 \%$ of $\mathrm{SO}_{2}$ from the atmosphere (Chin et al., 2000). The importance of dry deposition in the global sulphur budget is the reason why we target it for improvement in UKESM1. Dry deposition of $\mathrm{SO}_{2}$ in ESMs is generally represented by a resistance in series approach (e.g. Archibald et al., 2020; Wu et al., 2020). Deposition of $\mathrm{SO}_{4}^{2-}$ is mainly via wet processes (approximately 90\%, Chin et al., 2000), including gravitational settling and rain out. Deposition processes are necessarily parametrized in global models because they occur at sub-grid scales and this contributes to model uncertainty. Further, observational data sets are sparse and frequently temporally and spatially limited, hindering model evalaution of deposition processes.

The main challenge in evaluating model's ability to capture historical trends in sulphur species is the scarcity of observational data. Following the increasingly detrimental impacts of rising $\mathrm{SO}_{2}$ emissions and $\mathrm{SO}_{4}^{2-}$ on acid deposition, air quality and human health, monitoring networks were set up in Europe (Torseth et al., 2012) and America (MACTEC-Engineering and Consulting, 2005) in the 1970's and 1980's. Rising pollution in Asia also led to the establishment of the The Acid Deposition 
Monitoring Network in East Asia (EANET) in 2001 (e.g. Wang et al., 2008). Since the early 2000's satellite observations of near surface $\mathrm{SO}_{2}$ have also become available. Of these, the satellite data sets with the best temporal resolution and spatial coverage for $\mathrm{SO}_{2}$ are from the Ozone Monitoring Instrument aboard the NASA Earth Observing System Aura spacecraft (Fioletov et al., 2016). Although biases in the $\mathrm{SO}_{2}$ retrieval from OMI limit its use at high and low latitudes in winter and over ares with low atmospheric loading, they do provide valuable information over regions where there are no long term, or even any ground-based observations (Li et al., 2020; Levelt et al., 2018).

This paper is configured as follows; the model (UKESM1), the model simulations, observation data sets and modifications to UKESM1's $\mathrm{SO}_{2}$ dry deposition parameterization are described in Section 2. In Section 3 we evaluate UKESM1 against observations of surface $\mathrm{SO}_{2}$ and $\mathrm{SO}_{4}^{2-}$ and total column $\mathrm{SO}_{2}$. In Section 4 we assess the impact of the modifications to UKESM1's $\mathrm{SO}_{2}$ dry deposition parameterization. The discussion and conclusions are presented in Sections 5 and 6.

\section{Methods}

\subsection{UKESM1}

UKESM1 is the latest generation Earth System (ES) model to be developed in the UK. UKESM1 has HadGEM3-GC3.1 (Kuhlbrodt et al., 2018; Williams et al., 2018) as its physical-dynamical core. HadGEM3-GC3.1 is comprised of the Global Atmosphere 7.1 (GA7.1) configuration of the Unified Model (UM) (Walters et al., 2019; Mulcahy et al., 2018); the Nucleus for European Modelling of the Ocean (NEMO) model (Storkey et al., 2018); the Los Alamos Sea Ice Model (CICE, Ridley et al., 2018) and the Joint UK Land Environment Simulator (JULES) land surface model (Best et al., 2011). The additional ES process models include the stratospheric-tropospheric (StratTrop) version of the United Kingdom Chemistry and Aerosol (UKCA) model (Archibald et al., 2020), the Model of Ecosystem Dynamics, nutrient Utilisation, Sequestration and Acidification, (MEDUSA, Yool et al., 2013) and the terrestrial biogeochemistry component of JULES (Clark et al., 2011). UKESM1 is described in detail, along with its component models and the coupling between them, by Sellar et al. (2019). The aerosol scheme used in the HadGEM3-GC3.1 (GLOMAP-Mode, Mann et al., 2010)), including $\mathrm{SO}_{2}$ emissions and chemistry, is described in detail by Mulcahy et al. (2020). In UKESM1 the land and atmosphere share a regular latitude-longitude grid with a resolution of $1.25^{\circ} \times 1.875^{\circ}$ (approximately $135 \mathrm{~km}$ at the mid latitudes). There are 85 vertical levels on a terrain following hybrid height coordinate with a model lid at $85 \mathrm{~km}$ above sea level and 50 of these levels below $18 \mathrm{~km}$. The ocean has a horizontal resolution of $1^{\circ}$ and 75 vertical levels. While the atmospheric time step of the model physics is 20 minutes, due to the inherent computational cost of the chemistry and aerosol components, both of these components are called once per hour.

In UKESM1 the $\mathrm{SO}_{2}$ emissions, including anthropogenic sources are from the CMIP6 inventory (Feng et al., 2020). Large explosive volcanic sources and biomass burning sources are not interactively modelled, but prescribed using the CMIP6 stratospheric aerosol climatology (Sellar et al., 2019) and van Marle et al. (2017) emissions inventory respectively. Continuously 
degassing volcanic sources are also included as present-day, three-dimensional, temporally fixed (i.e. no seasonal variation) fields (Dentener et al., 2006). Emissions from the energy and industrial sectors are all emitted into the first model layer. We summarize the loss of $\mathrm{SO}_{2}$ from the atmosphere via oxidation, wet and dry deposition here, but for a detailed description of these processes in UKESM1 the reader is referred to Archibald et al. (2020) and Mulcahy et al. (2020). Gas phaser and aqueous phase oxidation of $\mathrm{SO}_{2}$ to $\mathrm{SO}_{4}^{2-}$ is represented by the reactions shown in Table 1 (Pham et al., 1996; Sander et al., 2003; Kreidenweis et al., 2003). Dry deposition of $\mathrm{SO}_{2}$ is parameterized following the resistance in series approach originally developed by Wesely (1989) (see Section 2.2.1). Loss via wet deposition is the $\mathrm{SO}_{2}$ that is scavenged and subsequently converted to $\mathrm{SO}_{4}^{2-}$ in rainwater. It is parameterized as a first-order loss rate, calculated as a function of UKESM1's three-dimensional convective and large-scale precipitation (Archibald et al., 2020; O'Connor et al., 2014). Sulphate aerosol is also removed from the atmosphere by dry and wet deposition (Mulcahy et al., 2020). The aerosol dry deposition and sedimentation are represented by a resistance in series approach similar to that used for gaseous species, but which also accounts for aerosol size (Mann et al., 2010). Wet deposition is parameterized in UKESM1 by an in-cloud convective plume scavenging scheme following the approach described by Kipling et al. (2013) and by nucleation scavenging (Mulcahy et al., 2020).

Table 1. Summary of $\mathrm{SO}_{2}$ oxidation chemistry in UKEMS1

\begin{tabular}{l}
\hline Gas phase reactions \\
\hline $\mathrm{SO}_{2}+\mathrm{OH} \rightarrow \mathrm{SO}_{3}+\mathrm{HO}_{2}$ \\
$\mathrm{SO}_{2}+\mathrm{O}_{3} \rightarrow \mathrm{SO}_{3}$ \\
$\mathrm{SO}_{3}+\mathrm{H}_{2} \mathrm{O} \rightarrow \mathrm{H}_{2} \mathrm{SO}_{4}+\mathrm{H}_{2} \mathrm{O}$ \\
\hline Aqueous phase reactions \\
\hline $\mathrm{HSO}_{3}^{-}+\mathrm{H}_{2} \mathrm{O}_{2} \rightarrow \mathrm{SO}_{4}^{2-}$ \\
$\mathrm{HSO}_{3}^{-}+\mathrm{O}_{3} \rightarrow \mathrm{SO}_{4}^{2-}$ \\
$\mathrm{SO}_{3}^{2-}+\mathrm{O}_{3} \rightarrow \mathrm{SO}_{4}^{2-}$ \\
\hline
\end{tabular}

\section{2 $\mathrm{SO}_{2}$ dry deposition parameterization}

In the "resistance in series" approach originally developed by Wesely (1989) dry deposition flux is proportional to the atmospheric concentration of a species multiplied by its deposition velocity (Eqn. 1). The dry deposition velocity is calculated by analogy with electrical resistance as shown in Eqn. 2 where $\mathrm{R}_{a}$ is aerodynamic resistance to gas transport through the near surface turbulent layer, $\mathrm{R}_{b}$ is resistance to gas transfer across a quasi-laminar sublayer surrounding the receptor surface and $\mathbf{R}_{c}$ is structural resistance to deposition of the receptor surface itself. For a detailed description of this approach, see Wesely 
$F=V_{d} \times C$

$V_{d}=\frac{1}{R_{a}+R_{b}+R_{c}}$

The surface or canopy resistance to deposition, $R_{c}$, is the most difficult of the three resistances to parameterize as it is sensitive to biochemical details of the individual receptor surfaces. $R_{c}$ is typically a function of the following receptor-specific resistances: (i) $R_{\text {stom }}$, canopy stomatal resistance, combined with the mesophyll resistance $\left(R_{m}\right)$ of a given plant, (ii) $R_{c u t}$, canopy cuticle or external leaf resistance and (iii) soil resistance $R_{\text {soil }}$, combined with an in-canopy resistance $R_{\text {inc }}$, describing the turbulent transport of a gas through the plant foliage to the ground. For surfaces not covered with vegetation (e.g. open water, bare soil or snow covered surfaces), $R_{c}$ is made equal to one of; $R_{\text {water }}, R_{\text {soil }}, R_{\text {snow }}$ (Erisman et al., 1994; Zhang et al., 2003).

\subsubsection{Modifications to UKESM1's $\mathrm{SO}_{2}$ dry deposition parameterization}

In this study we investigate two changes to the $\mathrm{SO}_{2}$ dry deposition parameterization in UKESM1. Firstly, we account for a key omission in the UKESM1 calculation of $R_{c u t}$ and $R_{\text {soil }}$ in that no account is taken as to whether the receptor surface is wet or dry, nor of the near surface relative humidity or soil $\mathrm{pH}$. Observational studies suggest that $\mathrm{SO}_{2}$ dry deposition (through a decrease in $R_{c}$ ) is significantly more efficient over wet surfaces compared to dry surfaces, as well as for increasing values of near surface relative humidity (e.g., Garland and Branson, 1977; Fowler, 1978; Erisman and Baldocchi, 1994) due to the high solubility of $\mathrm{SO}_{2}$ in water. Based on these findings we extend the calculation of $R_{c u t}$ for $\mathrm{SO}_{2}$ in UKESM1 to be a function both of whether the model vegetation is wet or dry and to the near surface relative humidity. This change allows a surface to remain wet after rainfall for a period of three hours, where previously it would have been "dry" immediately after the rainfall event. $R_{\text {soil }}$ for $\mathrm{SO}_{2}$ is also made a function of near surface relative humidity. These changes are referred to as $\mathrm{R}_{\text {surf }}$ - $\bmod$ and will impact $\mathrm{SO}_{2}$ dry deposition over land surfaces. Our approach closely follows that of Erisman and Baldocchi (1994); Erisman et al. (1994) and interested readers are referred to those two articles for more detail. Secondly, we change the the surface resistance term for $\mathrm{SO}_{2}$ dry deposition to water $\left(R_{\text {water }}\right)$ from an erroneously high value of $148 \mathrm{~s} \mathrm{~m}^{-1}$ to $1 \mathrm{~s} \mathrm{~m}^{-1}$ to better reflect the high solubility of $\mathrm{SO}_{2}$ in water. While lower than the value of $20 \mathrm{~s} \mathrm{~m}^{-1}$ used by Zhang et al. (2003), it reflects the small, observed value of $0.004 \mathrm{~s} \mathrm{~m}^{-1}$ from Garland and Branson (1977). This change is referred to as $\mathrm{R}_{\text {water }}$-mod and will impact $\mathrm{SO}_{2}$ dry deposition predominantly over the ocean.

In addition to the primary changes to the $\mathrm{SO}_{2}$ dry deposition parameterization $\left(\mathrm{R}_{\text {water }}\right.$-mod and $\mathrm{R}_{\text {surf }}$-mod), we also include two secondary modifications. These are (1) an update in the calculation of the stability parameter $(z / L)$ to better describe dry 
deposition in very stable atmospheric conditions, and (2) a bug fix in the dimethyl sulphoxide (DMSO) chemistry. The stability parameter $(z / L)$ describes the flux profile relationship and is important for calculating the $\mathrm{R}_{a}$ in Eqn. 2. Here it is updated from the calculation given by Dyer (1974) to that described by Holtslag and Bruin (1988). We also reduce the reference height for dry deposition $(z)$ from $50 \mathrm{~m}$ to $10 \mathrm{~m}$ in line with Holtslag and Bruin (1988). The reference height is the height below which there is no turbulence in very stable conditions and is also important for calculating $\mathrm{R}_{a}$. The changes to $z / L$ and $z$ act to reduce the rate at which the deposition velocity decreases in very stable conditions. The DMSO bug fix corrects the equation for dimethyl sulphide (DMS) oxidation by OH (see Reaction R1) in UKCA's StratTrop mechanism, where the products incorrectly contain more sulphur atoms than the reactants. We substitute Reaction R1 with Reactions R2 and R3. This reduces the $\mathrm{SO}_{2}$ yield to a maximum of 0.84, which may be further reduced as DMSO deposits to the Earth's surface. However, the changes in simulated $\mathrm{SO}_{2}$ are actually only of the order of $1 \%$ as anthropogenic sources are not affected by this change. Although the secondary changes incorporate important updates in to the model, their impact on atmospheric $\mathrm{SO}_{2}$ loading is small in comparison to that driven by $R_{\text {water }}$-mod and $R_{\text {surf }}-\bmod$ and we do not discuss it here.

$\mathrm{DMS}+\mathrm{OH} \rightarrow \mathrm{SO}_{2}+\mathrm{MSA}$

$\mathrm{DMS}+\mathrm{OH} \rightarrow 0.6 \mathrm{SO}_{2}+0.4 \mathrm{DMSO}+\mathrm{CH}_{3} \mathrm{O}_{2}$

$\mathrm{DMSO}+\mathrm{OH} \rightarrow 0.6 \mathrm{SO}_{2}+0.4 \mathrm{MSA}$.

\subsection{Model simulations}

For this evaluation we initially use 4 simulations from the 19 member ensemble of historical simulations that were conducted for UKESM1's contribution to CMIP6 (Sellar et al., 2019; Tang, 2019). The historical simulations cover the period from 1850 to the end of 2014, thus modelling the evolution of climate and composition since the pre-industrial era. These simulations are forced by transient external forcings of solar variability, land use, well-mixed greenhouse gases and other trace gas emissions and aerosols. The volcanic forcing due to the stratospheric injection of $\mathrm{SO}_{2}$ from volcanic eruptions is prescribed as a zonal mean climatology of the stratospheric aerosol optical properties over the historical period. All forcings and how they are implemented in UKESM1 are described fully in Sellar et al. (2019). Each historical ensemble member was initialised from a different date in the pre-industrial control simulation (Yool et al., 2020). We use monthly mean output for surface $\mathrm{SO}_{2}$ and $\mathrm{SO}_{4}^{2-}$ concentrations, and $\mathrm{SO}_{2}$ dry deposition flux. We use a second four member ensemble of historical simulations to evaluate the impact of the changes to the $\mathrm{SO}_{2}$ dry deposition parameterization described in Section 2.2.1, hereafter this ensemble is referred to as UKESM1-SO2. The UKESM1-SO2 historical simulations are set up and run as for the UKESM1 historical 
simulations.

Table 2. Summary of model configurations used in this study

\begin{tabular}{lcc}
\hline & UKESM1 & UKESM1-SO2 \\
\hline Simulation & Historical & Historical \\
No. of members & 4 & 4 \\
Modifications & - & (1) $\mathrm{R}_{\text {water }}$-mod and $\mathrm{R}_{\text {surf }}$-mod \\
& & (2) Update to $z / L$ and $z=10 \mathrm{~m}$ \\
& (3) DMSO chemistry bug fix
\end{tabular}

\subsection{Ground based observations}

We compare the modelled surface $\mathrm{SO}_{2}$ and $\mathrm{SO}_{4}^{2-}$ concentrations to observations from the Clean Air Status and Trends Network (CASTNet, http://epa.gov/castnet/javaweb/index.html, Finkelstein et al., 2000) and the European Monitoring and Evaluation Program (EMEP, http://ebas.nilu.no/; Torseth et al., 2012). CASTNet provides surface observations of mean seasonal $\mathrm{SO}_{2}$ and $\mathrm{SO}_{4}^{2-}$ concentrations which are available from 1987 to the present at 97 sites situated in the United States of America (USA). In this study we used observations from the CASTNet sites designated as "western reference" or "eastern reference". The reference sites have been reporting measurements since at least 1990 and are used for determining long term trends, (e.g., Clarke et al., 1997; Holland et al., 1998; MACTEC-Engineering and Consulting, 2005; Baumgardner et al., 2002). There are 16 western reference sites and 33 eastern reference sites which are located in the continental USA to the west and east of $100^{\circ} \mathrm{W}$ respectively (MACTEC-Engineering and Consulting, 2005). The eastern region is significantly more polluted than the western region due to the larger number of $\mathrm{SO}_{2}$ sources there. We therefore keep the western and eastern data sets separate to assess how UKESM1 performs in the two regions. Hereafter, we refer to the eastern and western USA regions as USA-E and USA-W, respectively. For this evaluation we used the mean seasonal surface concentrations for $\mathrm{SO}_{2}$ and $\mathrm{SO}_{4}^{2-}$ which are determined from hourly measurement data. Details of the quality control procedures and of how the the mean seasonal concentrations are calculated are given in (Baumgardner et al., 2002).

We also evaluate the simulated $\mathrm{SO}_{2}$ dry deposition flux from UKESM1 against observations from CASTNet, using the same eastern and western reference sites that were used to evaluate surface $\mathrm{SO}_{2}$ and $\mathrm{SO}_{4}^{2-}$ concentrations. The CASTNet deposition fluxes are derived using modelled deposition velocities rather than directly measured fluxes, which are difficult to obtain due to the requirement for extensive instrumentation and technical resource. Direct measurements of $\mathrm{SO}_{2}$ dry deposition flux are therefore temporally and spatially limited, and not suitable for evaluating long term trends. To derive the $\mathrm{SO}_{2}$ dry deposition fluxes, measurements of $\mathrm{SO}_{2}$ concentration are combined with routine meteorological measurements, information on the land 
use type and LAI at the measurement site. This data is then combined with modelled deposition velocities from the Multi Layer Model (MLM, Meyers et al., 1998; Saylor et al., 2014). The methodology used to derive the $\mathrm{SO}_{2}$ dry deposition fluxes for CASTNet is described in Clarke et al. (1997); Baumgardner et al. (2002). While the modelled $\mathrm{SO}_{2}$ dry deposition fluxes can be under-predicted by approximately 30\% (Clarke et al., 1997), it is considered to be the best available approach to regional scale assessment of dry deposition (Finkelstein et al., 2000; Baumgardner et al., 2002; E. Sickles and Shadwick, 2007; Sickles and Shadwick, 2007). This approach has been used to determine $\mathrm{SO}_{2}$ dry deposition fluxes for CASTNet since 1987 (e.g., Clarke et al., 1997; Baumgardner et al., 2002) and to assess global and regional scale models (Vet et al., 2014; Tan et al., 2018; Tang et al., 2018).

Surface $\mathrm{SO}_{2}$ and $\mathrm{SO}_{4}^{2-}$ concentrations have been monitored at EMEP sites for the period 1972 - present (Torseth et al., 2012). In this study we have used observations of surface concentration of $\mathrm{SO}_{2}$ and $\mathrm{SO}_{4}^{2-}$ from 144 and 99 sites respectively, although not all sites have measurements over the full period. We use monthly mean observations for both species. $\mathrm{No}_{2}$ dry deposition data were available from EMEP. The locations of the CASTNet and EMEP sites used in this study are shown in Figure 1.

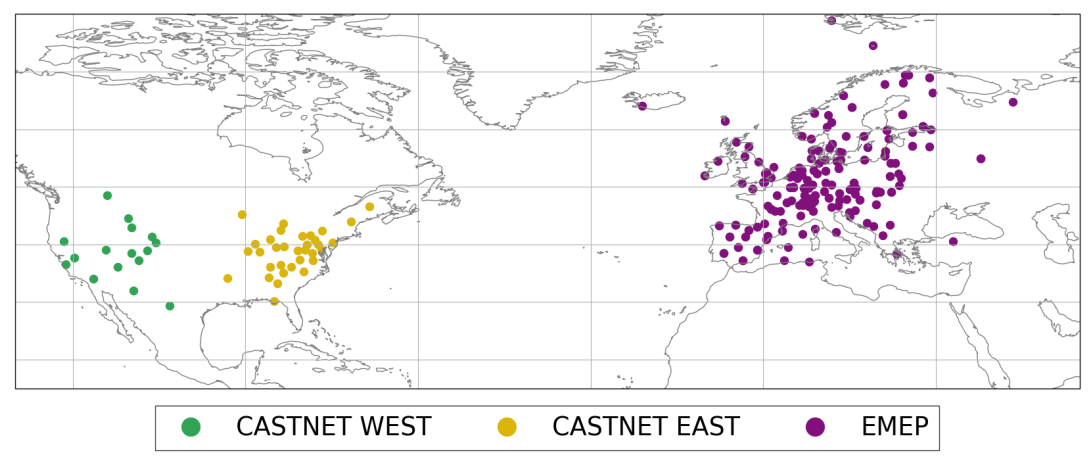

Figure 1. Map of the locations of the CASTNet and EMEP measurement sites used in this study.

\subsection{Data processing}

For this evaluation we calculated seasonal averages for the modelled surface $\mathrm{SO}_{2}$ and $\mathrm{SO}_{4}^{2-}$ concentrations and for the EMEP observational data. The seasonal periods were defined as December-January-February (DJF), March-April-May (MAM), JuneJuly-August (JJA) and September-October-November (SON). The CASTNet data for all variables was available as seasonal averages for these periods. Model grid cell output was co-located with the CASTNet and EMEP measurement sites. In some cases, this resulted in model data from a particular grid cell being compared with more than one measurement site. For the time series analysis, regional means and standard deviations were calculated across the sites in the USA-E, USA-W and EMEP 
regions. Although there is spatial variation in the surface $\mathrm{SO}_{2}$ and $\mathrm{SO}_{4}^{2-}$ concentrations across Europe, for example concentrations are relatively low in Scandinavia, but are much higher in South East Europe, it is less easy to classify "clean" and "polluted" regions at the global model scale. Therefore we classify Europe as a single region. For the spatial analysis and calculation of time series statistics, we calculate mean values over the whole time series, i.e. 1987-2014 and for two time slices at the start (1990-1995) and end of the time series (2009-2014). We investigate the two time slices to assess the model's performance during the different pollution levels at the start and end of the the time series. We determine the rate of change (trend) in the surface concentrations by calculating the linear regression for 1987-2014, 1990-1995 and 2009-2014.

\subsection{Satellite observations}

Total column $\mathrm{SO}_{2}\left(\mathrm{TCSO}_{2}\right)$ measurements came from the Ozone Monitoring Instrument (OMI), which were obtained from the Goddard Earth Sciences Data and Information Services Centre (https://aura.gesdisc.eosdis.nasa.gov/data/Aura_OMI_Level2/ OMSO2.003) ( $\mathrm{Li}$ et al., 2020). OMI is situated on-board NASA's polar-orbiting Aura satellite launched in 2004 with a local overpass time of approximately 13:45. OMI has a nadir footprint of $13 \mathrm{~km} \times 24 \mathrm{~km}$ and a spectral viewing range of 270 to $500 \mathrm{~nm}$ (Levelt et al., 2018). The $\mathrm{TCSO}_{2}$ product is quality controlled for cloud radiation fraction $>0.0$ and $<0.5$, solar zenith angle $<65^{\circ}$, the South Atlantic Anomaly flag $=0$, ice cover flag $=0$, the air mass factor $($ AMF $)>0.3$ and $\mathrm{TCSO}_{2}>-1.0$ Dobson unit (DU). Background $\mathrm{TCSO}_{2}$ average values tend to be positive near-zero quantities (i.e. just above 0.0), where some soundings are slightly negative. If only positive $\mathrm{TCSO}_{2}$ were incorporated in the background averages, this would positively skew the true value.

For a robust comparison between model simulations and satellite data, to reduce sampling (representation) errors, both data sets typically require spatio-temporal co-location. To achieve this, high temporal resolution (e.g. 3 hourly or 6 hourly) model output of 3D tracer and pressure fields are required over the analysis period to capture e.g. diurnal variability (Pope et al., 2016; Monks et al., 2017). However, this is difficult when using standard climate model simulations, including those used in this study, which typically output monthly means due to their long term climate focus. In this comparison we performed tests to show that using the monthly mean model output was suitable given the relatively uniform diurnal cycle of $\mathrm{SO}_{2}$ emissions. For these tests we made initial comparisons of model output and satellite data using 6 hourly and monthly mean output from the same UKESM1 simulation. We found that the temporal sampling of the model was not overly critical for $\mathrm{SO}_{2}$, i.e. modelled $\mathrm{SO}_{2}$ has a sufficiently long lifetime to dampen the influence of diurnal sampling of the model. Further details on the $\mathrm{TCSO}_{2}$ product, how it was processed to obtain $\mathrm{TCSO}_{2}$ values and the assessment of the temporal resolution is given in Pope and Chipperfield (2021). 


\section{Evaluation of trends and biases in modelled $\mathrm{SO}_{2}$ and $\mathrm{SO}_{4}^{2-}$ concentrations}

\subsection{Time series analysis of surface concentrations of $\mathrm{SO}_{2}$ and $\mathrm{SO}_{4}^{2-}$ for 1987-2014}

UKESM1 simulations of surface of $\mathrm{SO}_{2}$ and $\mathrm{SO}_{4}^{2-}$ concentrations are compared with observations from the CASTNet and EMEP networks for the period 1987-2014 in Figure 2. The statistics summarizing the model bias and trends over this period as well as for the 1990-1995 and 2009-2014 time slices are shown in Tables 3 and 4. We find that UKESM1 captures the historical reduction in surface $\mathrm{SO}_{2}$ and $\mathrm{SO}_{4}^{2-}$ concentrations, but was less able to simulate the finer detail in the temporal trends. UKESM1 over-predicts surface $\mathrm{SO}_{2}$ concentrations in all three regions, but the direction of the model's bias in surface $\mathrm{SO}_{4}^{2-}$ concentrations is spatially variable.
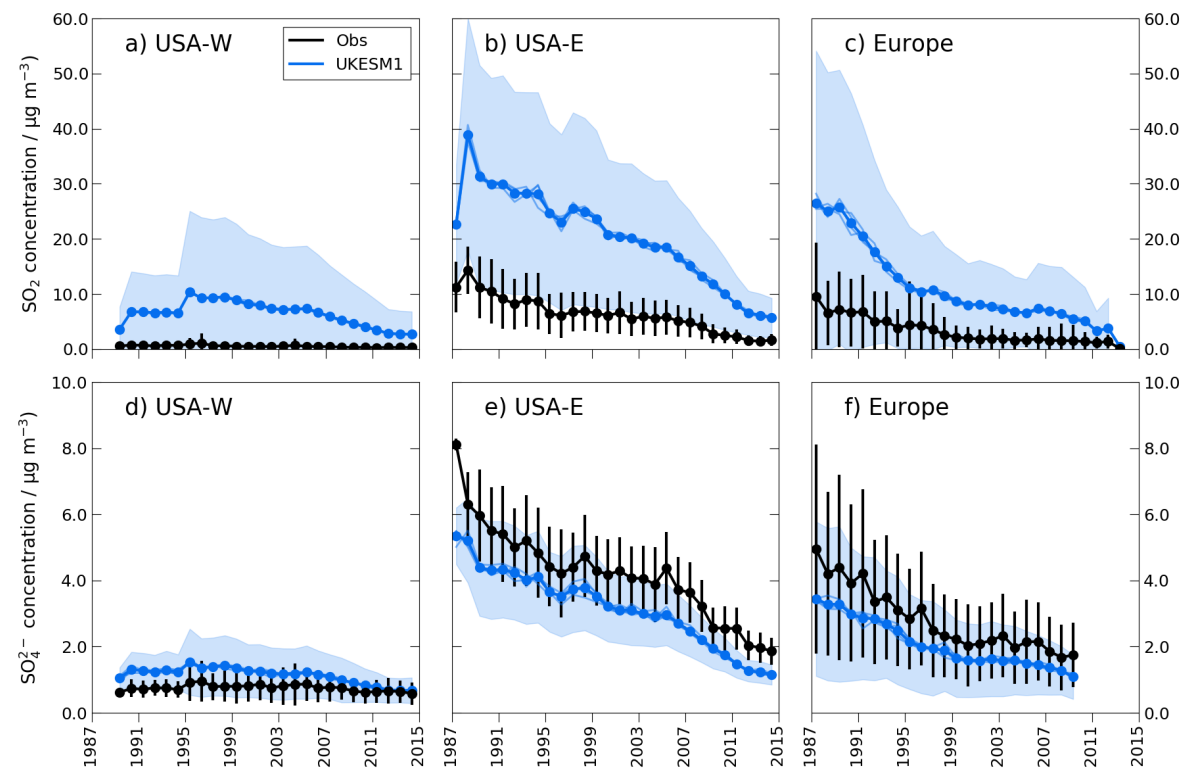

Figure 2. Time series of observed and modelled mean annual surface $\mathrm{SO}_{2}$ (top row) and $\mathrm{SO}_{4}^{2-}$ (bottom row) concentrations for USA-W (a, c), USA-E (b, d) and Europe (c, e). Each point in the time series represents the mean across the measurement sites in the region. Note that the vertical scale for $\mathrm{SO}_{2}(\mathrm{a}-\mathrm{c})$ is a factor of 6 larger than that for $\mathrm{SO}_{4}^{2-}$.

Figures 2a-c show that in both Europe and USA-E the modelled surface $\mathrm{SO}_{2}$ concentrations are over-predicted, particularly at the start of the time series, and decrease too rapidly. Over Europe, the observed surface $\mathrm{SO}_{2}$ concentrations decrease at a rate of $0.72 \mu \mathrm{g} \mathrm{m}^{-3} \mathrm{y}^{-1}$ in the period 1990-1995 which slows to $0.38 \mu \mathrm{g} \mathrm{m}^{-3} \mathrm{y}^{-1}$ by 2009-2014. However, the modelled surface $\mathrm{SO}_{2}$ concentrations decrease much too rapidly at the start of the time series, reducing by $2.52 \mu \mathrm{g} \mathrm{m}^{-3} \mathrm{y}^{-1}$ for $1990-1995$. This slows to $-1.31 \mu \mathrm{g} \mathrm{m}^{-3} \mathrm{y}^{-1}$ by 2009-2014, but is still too rapid compared to the observations. Over USA-E the observed surface $\mathrm{SO}_{2}$ concentrations decrease at similar rates of between $0.36 \mu \mathrm{g} \mathrm{m}^{-3} \mathrm{y}^{-1}$ and $0.25 \mu \mathrm{g} \mathrm{m}^{-3} \mathrm{y}^{-1}$ at the start and end of 
the time series. UKESM1 does capture this trend at the start of the time series, but simulates a too rapid reduction in surface $\mathrm{SO}_{2}$ concentrations after 2005 (see Figure 2b). UKESM1 simulates the sharp drop in surface $\mathrm{SO}_{2}$ concentrations that occurred in 1995 following the implementation of Phase 1 of the USA's Clean Air Act Amendments (McHale et al., 2021). However, following this event the model simulates relatively high surface $\mathrm{SO}_{2}$ concentrations for the period 1997-1999, rather than the sustained lower surface $\mathrm{SO}_{2}$ concentrations that are observed after 1995. In USA-W the observed surface $\mathrm{SO}_{2}$ concentrations remain steady from 1987 to 2014 due to there being fewer sources in this region. Figure 2a shows that UKESM1 simulates the steady surface $\mathrm{SO}_{2}$ concentrations at the start of the time series, albeit with a positive bias. However, after 1995 UKESM1 simulates decreasing surface $\mathrm{SO}_{2}$ concentrations in USA-W, which brings the modelled values in to better agreement with the observations, but introduces an artificial trend into the modelled time series.

UKESM1 over-predicts the annual mean surface $\mathrm{SO}_{2}$ concentrations in the polluted regions of Europe and USA-E by a factor of 3.2 to 3.4 over the period 1987-2014, although the absolute bias is higher USA-E (see Table 3). While the absolute magnitude of the bias in mean annual surface $\mathrm{SO}_{2}$ concentration is less in USA-W compared with the polluted regions, proportionally it is much larger, with the model simulating surface $\mathrm{SO}_{2}$ concentrations more than 10 times the observed values. The absolute magnitude of the bias in mean annual surface $\mathrm{SO}_{2}$ concentration decreased from 1990-1995 to 2009-2014 in all three regions (see Table 3 ) reflecting the model's more rapid decrease in surface $\mathrm{SO}_{2}$ concentrations relative the observations. However, the NMB values were slightly higher in 2009-2014 compared with 1990-1995.

Figures 2e-f show that UKESM1 better captures both the magnitude and the trends in surface $\mathrm{SO}_{4}^{2-}$ concentrations compared to surface $\mathrm{SO}_{2}$ concentrations. The model simulated surface $\mathrm{SO}_{4}^{2-}$ concentrations decreasing at a rate of $0.14 \mu \mathrm{g} \mathrm{m}^{-3} \mathrm{y}^{-1}$ (USA-E) and $0.12 \mu \mathrm{g} \mathrm{m}^{-3} \mathrm{y}^{-1}$ (Europe) compared with the observed trend of $0.16 \mu \mathrm{g} \mathrm{m}^{-3} \mathrm{y}^{-1}$ (see Table 4). UKESM1 does under-predict mean annual surface $\mathrm{SO}_{4}^{2-}$ concentrations in the polluted regions of USA-E and Europe, but the model bias is relatively small compared with the large over prediction of mean annual surface $\mathrm{SO}_{2}$ concentration (see Tables 3 and 4). We also note that there is a large range associated with the modelled and observed data, and that the mean surface $\mathrm{SO}_{4}^{2-}$ concentrations lie within these ranges. The model bias remained relatively constant over the period from 1987-2014 with values of $-0.95 \mu \mathrm{g} \mathrm{m}^{-3}$ (USA-E) and $-0.82 \mu \mathrm{g} \mathrm{m}^{-3}$ (Europe) for the period 1990-1995 decreasing to $-0.79 \mu \mathrm{g} \mathrm{m}^{-3}$ (USA-E) and $-0.66 \mu \mathrm{g} \mathrm{m}^{-3}$ (Europe) by 2009-2014 (see Table 4). The NMB was slightly higher for both regions in the later period, but the values remained low. The picture is different in USA-W where, in contrast to USA-E and Europe, UKESM1 over predicts mean annual surface $\mathrm{SO}_{4}^{2-}$ concentration by $150 \%$ over the period 1987-2014. Both the absolute model bias and the NMB is worse in 1990-1995 than in 2009-2014, which may be attributed to the model simulating a much faster decrease in mean annual surface $\mathrm{SO}_{4}^{2-}$ concentrations compared to the observed trend for the later period (see Table 4). 
https://doi.org/10.5194/acp-2021-238

Preprint. Discussion started: 28 April 2021

(C) Author(s) 2021. CC BY 4.0 License.

(c) (i)

Table 3. Statistics for mean annual surface $\mathrm{SO}_{2}$ concentrations at USA-W, USA-E and Europe. The mean and trend values are in $\mu \mathrm{g} \mathrm{m}^{-3}$ and $\mu \mathrm{g} \mathrm{m}^{-3} \mathrm{y}^{-1}$ respectively.

\begin{tabular}{|c|c|c|c|c|}
\hline & & 1987-2014 & 1990-1995 & 2009-2014 \\
\hline \multirow[t]{7}{*}{ USA-W } & Mean (obs) & 0.53 & 0.71 & 0.29 \\
\hline & Mean (model) & 6.45 & 7.29 & 3.40 \\
\hline & Bias & 5.92 & 6.58 & 3.11 \\
\hline & NMB & 11.57 & 9.25 & 10.63 \\
\hline & $\mathrm{R}$ & 0.81 & 0.88 & 0.22 \\
\hline & Trend (obs) & $-8.39 \times 10^{-3}$ & $-1.45 \times 10^{-2}$ & $-4.89 \times 10^{-3}$ \\
\hline & Trend (model) & $-4.12 \times 10^{-2}$ & $-5.74 \times 10^{-2}$ & -0.34 \\
\hline \multirow[t]{7}{*}{ USA-E } & Mean (obs) & 6.31 & 8.64 & 2.02 \\
\hline & Mean (model & 20.36 & 28.22 & 8.04 \\
\hline & Bias & 14.06 & 19.58 & 6.02 \\
\hline & NMB & 2.23 & 2.27 & 2.99 \\
\hline & $\mathrm{R}$ & 0.94 & 0.93 & 0.96 \\
\hline & Trend (obs) & -0.37 & -0.36 & -0.24 \\
\hline & Trend (model) & -0.98 & -0.52 & -1.05 \\
\hline \multirow[t]{7}{*}{ Europe } & Mean (obs) & 3.29 & 5.28 & 1.09 \\
\hline & Mean (model) & 11.12 & 16.69 & 3.62 \\
\hline & Bias & 7.83 & 11.41 & 2.53 \\
\hline & NMB & 2.38 & 2.16 & 2.32 \\
\hline & $\mathrm{R}$ & 0.97 & 0.92 & 0.97 \\
\hline & Trend (obs) & -0.27 & -0.72 & -0.38 \\
\hline & Trend (model) & -0.84 & -2.52 & -1.31 \\
\hline
\end{tabular}

\subsection{Spatial evaluation of surface $\mathrm{SO}_{2}$ and $\mathrm{SO}_{4}^{2-}$ concentrations}

Figures 3 and 4 show the spatial distribution of modelled and observed mean annual surface $\mathrm{SO}_{2}$ and $\mathrm{SO}_{4}^{2-}$ concentrations for the periods 1990-1995 and 2009-2014 for the USA and Europe. We find that UKESM1 captures the spatial distribution of surface $\mathrm{SO}_{2}$ and $\mathrm{SO}_{4}^{2-}$ concentrations over each region, simulating higher concentrations in USA-E, central Europe and eastern Europe where there are numerous large sources, and lower concentrations in USA-W and northern Europe which have much fewer sources and are relatively clean (see Figure A1). These figures also show the localised versus dispersed nature of the surface $\mathrm{SO}_{2}$ and $\mathrm{SO}_{4}^{2-}$ concentrations, with high $\mathrm{SO}_{2}$ concentrations located within $2-3$ grid boxes $(200-400 \mathrm{~km})$ of the emission sources (see Figure A1), while $\mathrm{SO}_{4}^{2-}$ is distributed more widely. UKESM1 is also able to simulate the range 
https://doi.org/10.5194/acp-2021-238

Preprint. Discussion started: 28 April 2021

(c) Author(s) 2021. CC BY 4.0 License.

(c) (i)

Table 4. Statistics for mean annual surface $\mathrm{SO}_{4}^{2-}$ concentrations at USA-W, USA-E and Europe. The mean and trend values are in $\mu \mathrm{g} \mathrm{m}{ }^{-3}$ and $\mu \mathrm{g} \mathrm{m}^{-3} \mathrm{y}^{-1}$ respectively.

\begin{tabular}{|c|c|c|c|c|}
\hline & & 1987-2014 & 1990-1995 & 2009-2014 \\
\hline \multirow[t]{7}{*}{ USA-W } & Mean (obs) & 0.74 & 0.76 & 0.63 \\
\hline & Mean (model) & 1.14 & 1.31 & 0.76 \\
\hline & Bias & 0.38 & 0.55 & 0.12 \\
\hline & NMB & 0.5 & 0.73 & 0.20 \\
\hline & $\mathrm{R}$ & 0.92 & 0.95 & 0.24 \\
\hline & Trend (obs) & $-7.16 \times 10^{-3}$ & $-3.41 \times 10^{-3}$ & $-7.73 \times 10^{-3}$ \\
\hline & Trend (model) & $-3.70 \times 10^{-3}$ & $-1.41 \times 10^{-2}$ & $-3.97 \times 10^{-2}$ \\
\hline \multirow[t]{7}{*}{ USA-E } & Mean (obs) & 4.19 & 5.06 & 2.26 \\
\hline & Mean (model) & 3.17 & 4.11 & 1.47 \\
\hline & Bias & -1.03 & -0.95 & -0.79 \\
\hline & NMB & -0.24 & -0.19 & -0.35 \\
\hline & $\mathrm{R}$ & 0.96 & 0.87 & 0.89 \\
\hline & Trend (obs) & -0.16 & -0.15 & -0.2 \\
\hline & Trend (model) & -0.14 & $-7.14 \times 10-2$ & -0.14 \\
\hline \multirow[t]{7}{*}{ Europe } & Mean (obs) & 2.82 & 3.49 & 1.75 \\
\hline & Mean (model) & 2.09 & 2.67 & 1.08 \\
\hline & Bias & -0.73 & -0.82 & -0.66 \\
\hline & NMB & -0.26 & -0.24 & -0.38 \\
\hline & $\mathrm{R}$ & 0.99 & 0.85 & - \\
\hline & Trend (obs) & -0.16 & -0.23 & - \\
\hline & Trend (model) & -0.12 & -0.11 & - \\
\hline
\end{tabular}

of concentrations observed across the USA-E region, for example, the lower $\mathrm{SO}_{2}$ and $\mathrm{SO}_{4}^{2-}$ concentrations in the north east USA bordering Canada. Figure 3 shows that surface $\mathrm{SO}_{2}$ and $\mathrm{SO}_{4}^{2-}$ concentrations are lower in 2009-2014 compared with 1990-1995 demonstrating the impact of emissions reductions policy across the USA, which the model also simulates well. However, the divide between higher concentrations in USA-E compared with lower concentrations in USA-W is still apparent for both species in the later period.

In Europe the highest mean annual surface $\mathrm{SO}_{2}$ and $\mathrm{SO}_{4}^{2-}$ concentrations were observed in central and eastern Europe and the South East (SE) of England (see Figure 4). Lower concentrations of both species were observed in Scandinavia, the Iberian peninsular, south west France and at Mace Head on the west coast of Ireland. Figure $4 \mathrm{c}$ shows that mean annual surface $\mathrm{SO}_{2}$ 

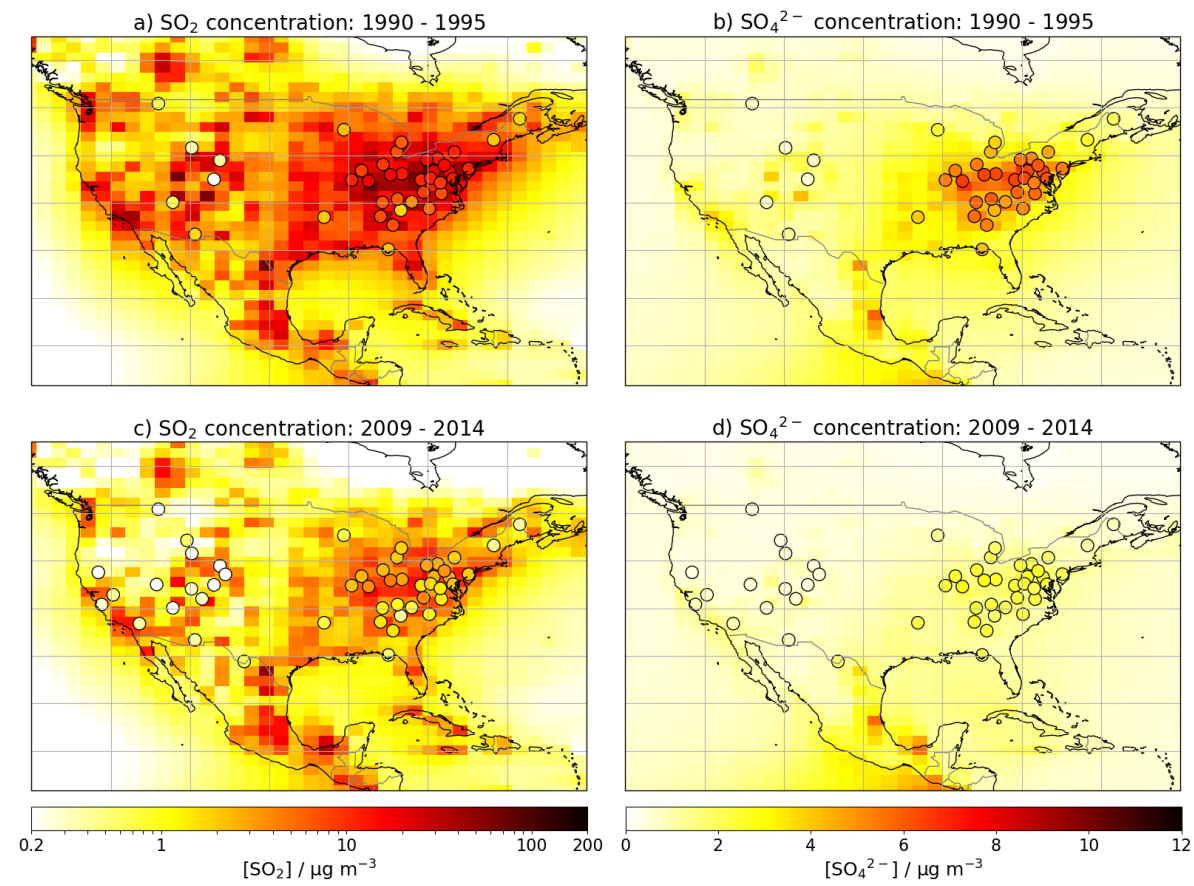

Figure 3. Mean annual surface $\mathrm{SO}_{2}$ concentration (a, c) and surface $\mathrm{SO}_{4}^{2-}$ concentration (b, d) for 1990-1995 (top row) and 2009-2014 (bottom row) for modelled output. Observations are plotted as black-edged circles on the same colour scale.

concentrations were uniformly lower in 2009-2014 due to the impact of air quality legislation over the last 30 years. UKESM1 reproduces the spatial distribution of mean annual $\mathrm{SO}_{2}$ concentration, but has large positive biases over most of region. The largest model biases were in Eastern and SE Europe from 1990-1995 where UKESM1 simulates mean annual surface $\mathrm{SO}_{2}$ concentrations of up to $100 \mu \mathrm{g} \mathrm{m}^{-3}$ compared with observed values of $10-30 \mu \mathrm{g} \mathrm{m}^{-3}$.

Figure $4 \mathrm{~b}$ shows that UKESM1 captures the low mean annual surface $\mathrm{SO}_{4}^{2-}$ concentrations in the northern and western regions of Europe and the high mean annual surface $\mathrm{SO}_{4}^{2-}$ concentrations in central Europe. However, the model under-predicts the spatial extent of the mean annual surface $\mathrm{SO}_{4}^{2-}$ concentrations across Europe. The largest biases of $5-7 \mu \mathrm{g} \mathrm{m}^{-3}$ occur in an area including northern Germany, Denmark, southern Sweden, eastern Poland, Switzerland, Belgium and the Netherlands. In comparison, UKESM1 under-predicts mean annual surface $\mathrm{SO}_{4}^{2-}$ concentrations by approximately $2-3 \mu \mathrm{g} \mathrm{m}^{-3}$ outside of this area. In Europe $\mathrm{SO}_{2}$ concentrations are uniformly lower in 2009-2014 compared with 1990-1995, especially in Central and Eastern Europe (see Figures $4 \mathrm{a}$ and c). However, the model continues to predict very high levels of $\mathrm{SO}_{2}$ in the $\mathrm{SE}$ region for 2009-2014 (see Figure 4c). 

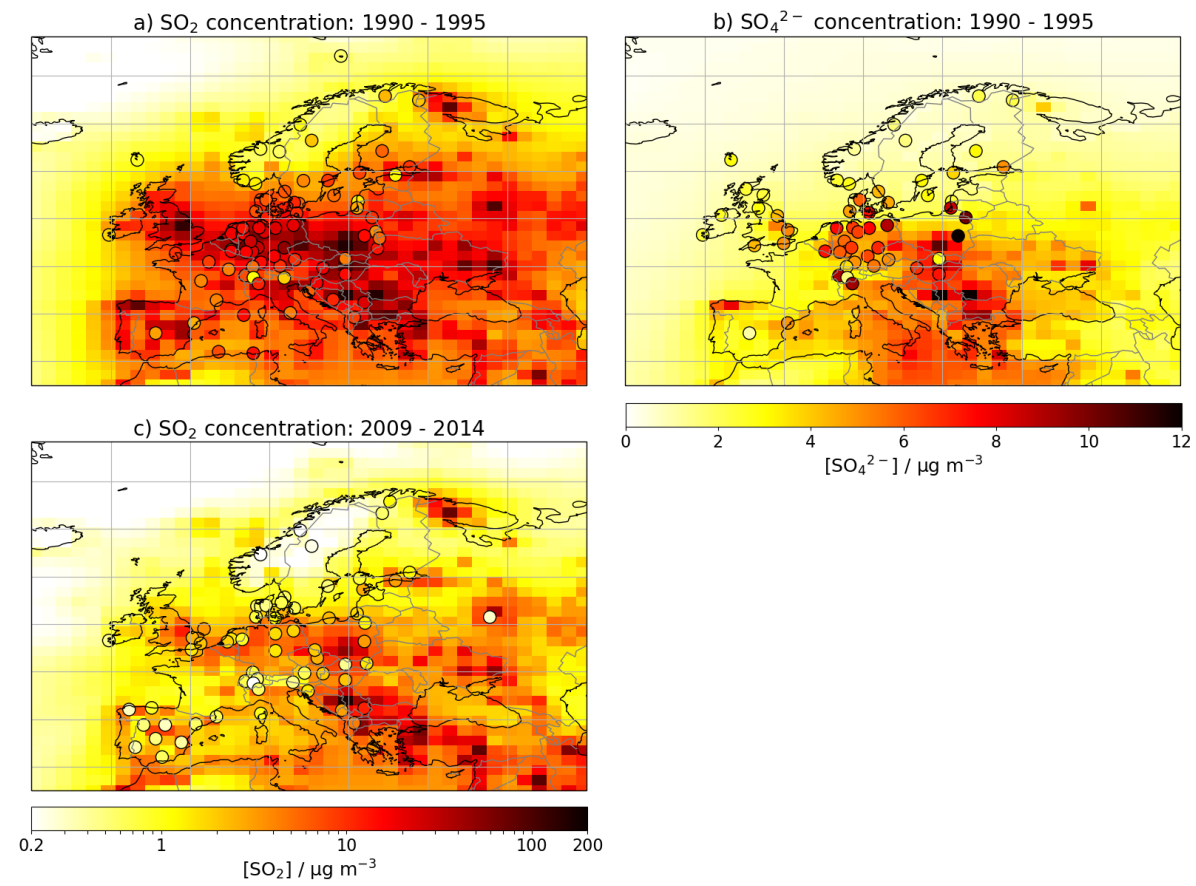

Figure 4. Mean annual surface $\mathrm{SO}_{2}$ concentration (a, c) for 1990-1995 (a) and 2009-2014 (b); surface $\mathrm{SO}_{4}^{2-}$ concentration for 1990-1995 (b, no data available for 2009-2014) for modelled output. Observations are plotted as black-edged circle on the same colour scale.

\subsection{Spatial distribution of model bias in surface $\mathrm{SO}_{2}$ and $\mathrm{SO}_{4}^{2-}$ concentrations}

Figures 5 and 6 show that the direction of the model biases is generally consistent across the regions. UKESM1 over-predicts mean annual surface $\mathrm{SO}_{2}$ concentration for all sites in both the USA-E and USA-W regions, and with the exception of some Scandinavian sites, across Europe. Figures 5 and 6 also show that mean annual surface $\mathrm{SO}_{4}^{2-}$ concentrations are generally under-predicted across the USA-E and European sites, while being over-predicted at the USA-W sites.

The model's over-prediction of mean annual surface $\mathrm{SO}_{2}$ concentration is largest close to the sources. For example, UKESM1 over-predicts surface $\mathrm{SO}_{2}$ concentrations by up to $50 \mu \mathrm{g} \mathrm{m}^{-3}$ in the central USA-E area, but only by around $10 \mu \mathrm{g} \mathrm{m}^{-3}$ at the surrounding sites. In Europe the largest biases of around 10-20 $\mu \mathrm{g} \mathrm{m}^{-3}$ tend to be distributed across the region due to the more distributed nature of the point sources and on average the model bias is lower than in USA-E. The model's tendency to overpredict $\mathrm{SO}_{2}$ concentrations to a greater extent close to the sources is also shown in the plots of NMB (see Figures 5c and 6c) and is likely why there is a larger range in the modelled mean annual surface $\mathrm{SO}_{2}$ concentrations averaged across the USA-E and European measurement sites compared with the observational values (see Figures $2 \mathrm{~b}$ and $\mathrm{c}$ ). Figures $5 \mathrm{~b}$ and $6 \mathrm{~b}$ show that UKESM1 generally under-predicts surface $\mathrm{SO}_{4}^{2-}$ concentration across the USA-E and European sites, with model biases of 
a) $\mathrm{SO}_{2}$ concentration: 1987 - 2014

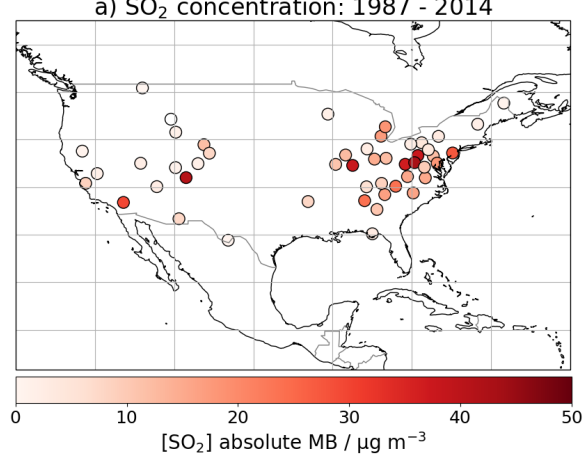

c) $\mathrm{SO}_{2} \mathrm{NMB}: 1987$ - 2014

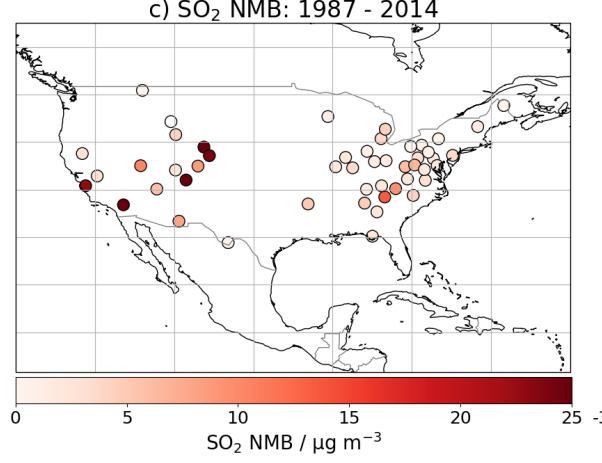

b) $\mathrm{SO}_{4}{ }^{2-}$ concentration: $1987-2014$

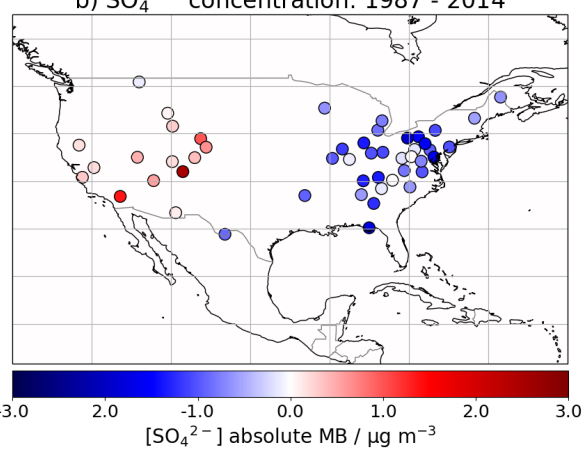

d) $\mathrm{SO}_{4}{ }^{2-} \mathrm{NMB}: 1987-2014$

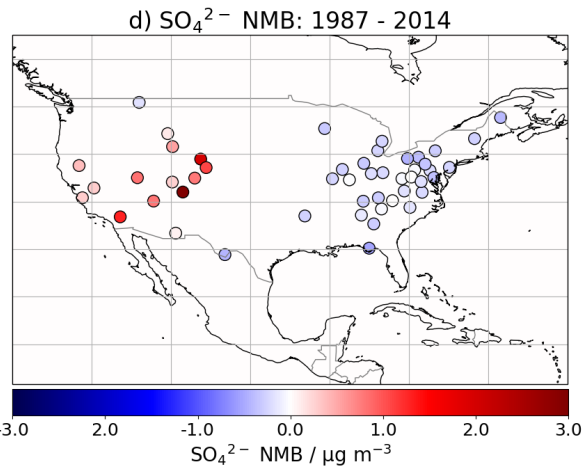

Figure 5. Geographic distribution of mean bias (UKESM1 - obs) in mean annual surface $\mathrm{SO}_{2}$ and $\mathrm{SO}_{4}^{2-}$ concentration at CASTNet site locations. The mean annual surface concentrations are calculated over the period 1987 to 2014. Absolute mean bias (MB) is shown in (a) and (b) and normalised mean bias (NMB) is shown in (c) and (d). Note that different scales are used for the $\mathrm{SO}_{2}$ model bias (a) and normalised mean bias (c).

in $\mathrm{SO}_{2}$, instead occurring at sites surrounding the large point sources. Similarly, in Europe the largest biases in surface $\mathrm{SO}_{4}^{2-}$ concentrations occur further north than the large biases in surface $\mathrm{SO}_{2}$ concentration, and in certain sites located near large sources, UKESM1 over-predicts surface $\mathrm{SO}_{4}^{2-}$ concentrations. The plots of NMB show that there is less spatial variation in the model bias for surface $\mathrm{SO}_{4}^{2-}$ concentrations reflecting UKESM1's ability to capture the more distributed nature of atmospheric $\mathrm{SO}_{4}^{2-}$. In USA-W UKESM1 over-predicts both $\mathrm{SO}_{2}$ and $\mathrm{SO}_{4}^{2-}$ concentrations at almost all of the sites (see Figure 5). For $\mathrm{SO}_{2}$ this is a consequence of the sparsely distributed measurement sites being located in rural regions remote from any of the sources in USA-W (Clarke et al., 1997; MACTEC-Engineering and Consulting, 2005; Baumgardner et al., 2002) (see also Figure A1). This results in some very large NMB values in USA-W (see Figure 5a). 
a) $\mathrm{SO}_{2}$ concentration: $1987-2014$

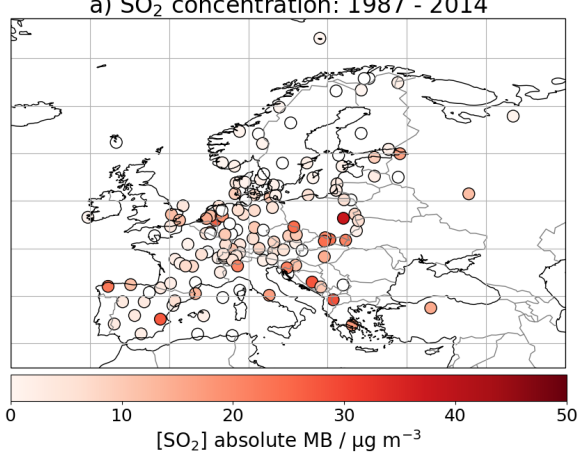

c) $\mathrm{NMB} \mathrm{SO}_{2}$ concentration: 1987 - 2014

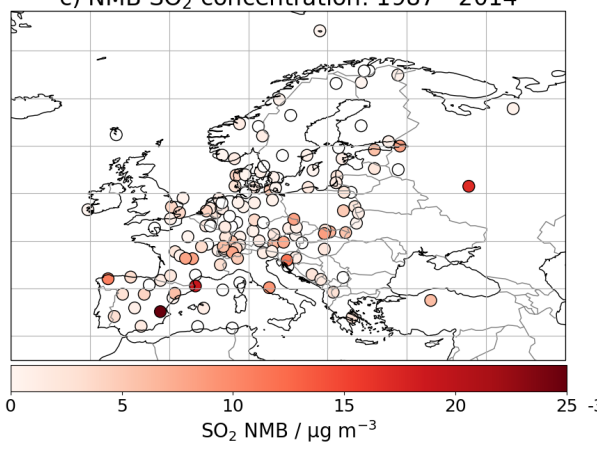

b) $\mathrm{SO}_{4}{ }^{2-}$ concentration: $1987-2014$

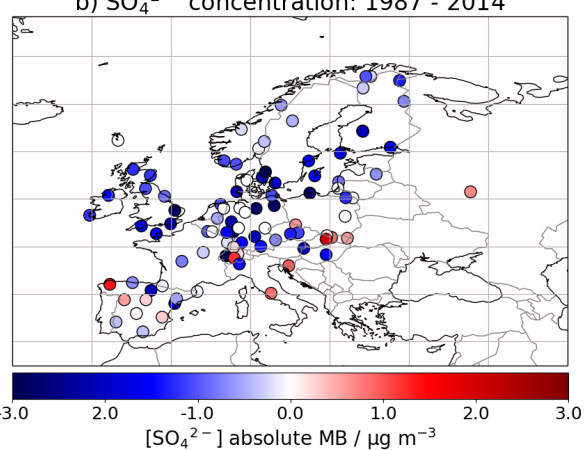

d) $\mathrm{NMB} \mathrm{SO}_{4}{ }^{2-}$ concentration: $1987-2014$

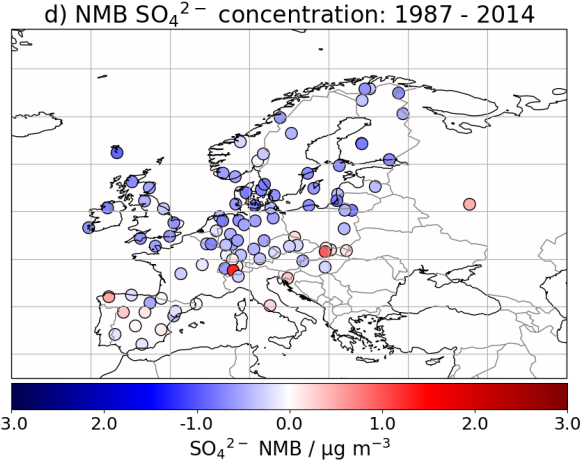

Figure 6. Geographic distribution of mean bias (UKESM1 - obs) in mean annual surface $\mathrm{SO}_{2}$ and $\mathrm{SO}_{4}^{2-}$ concentration at EMEP site locations. The mean annual surface concentrations are calculated over the period 1987 to 2014. Absolute mean bias is shown in (a) and (b) and normalised mean bias (NMB) is shown in (c) and (d). Note that different scales are used for the $\mathrm{SO}_{2}$ model bias (a) and normalised mean bias (c).

\subsection{Seasonal Cycles}

Figure 7 shows modelled and observed surface $\mathrm{SO}_{2}$ and $\mathrm{SO}_{4}^{2-}$ concentrations averaged seasonally for the period 1987-2014. The comparison between the model and observations is summarised for DJF and JJA in Table 5. The higher winter time $\mathrm{SO}_{2}$ concentrations are driven by greater emissions from coal fired power plants and domestic heating, and less oxidation. Conversely there are fewer emissions and higher oxidant concentrations in summer time. These cycles drive correspondingly low $\mathrm{SO}_{4}^{2-}$ concentrations in winter and high $\mathrm{SO}_{4}^{2-}$ concentrations in summer. Overall, we find that the model bias in surface $\mathrm{SO}_{2}$ and $\mathrm{SO}_{4}^{2-}$ concentrations depends on the season as well as the region and pollution levels.

The results presented in Sections 3.1 and 3.2 show that UKESM1 consistently over-predicts mean annual surface $\mathrm{SO}_{2}$ concentrations in the USA and Europe, however Figures 7a-c show that in the more polluted regions (USA-E and Europe), the magnitude of the bias is seasonal, although still with a large positive bias. UKESM1 is able to capture the seasonal cycle in surface $\mathrm{SO}_{2}$ concentrations over Europe, but the absolute model bias is larger in DJF compared with JJA (see Table 5). In 

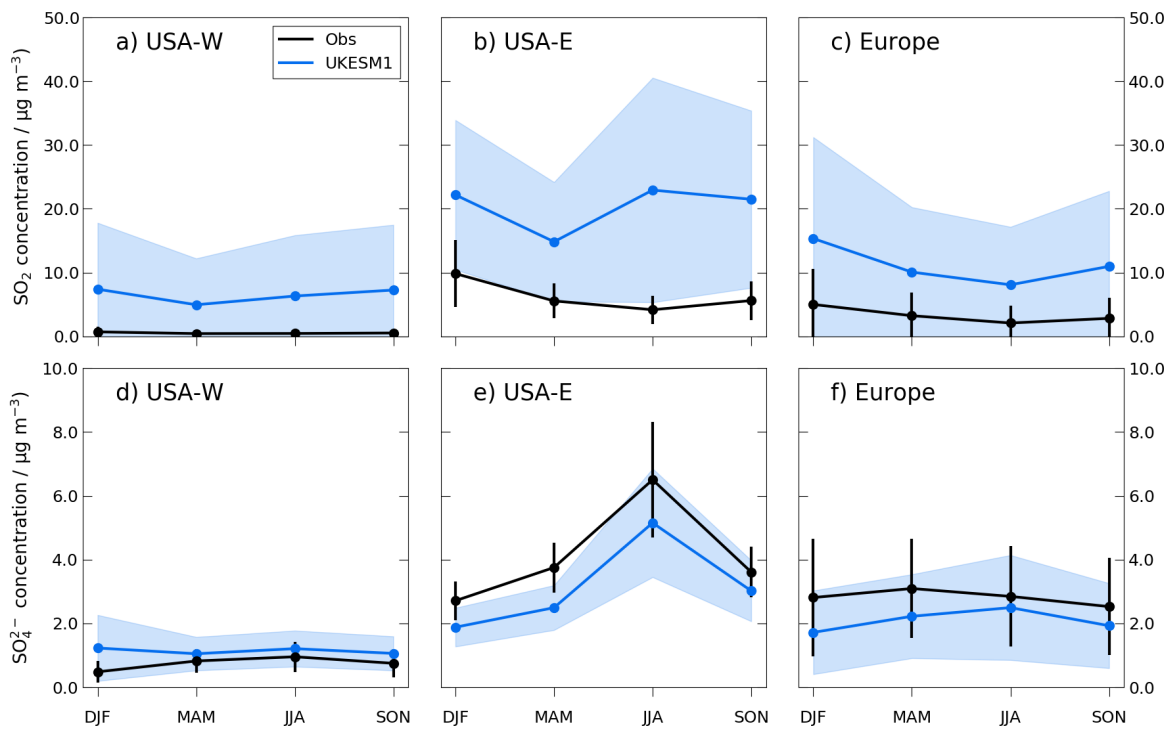

Figure 7. Modelled and observed seasonal mean surface $\mathrm{SO}_{2}$ concentration (top row) and surface $\mathrm{SO}_{4}^{2-}$ concentration (bottom row) for the period 1987-2014. USA-W, (a, d); USA-E, (b, e) and EMEP (c, e).

Table 5. Statistics for seasonal mean surface $\mathrm{SO}_{2}$ and $\mathrm{SO}_{4}^{2-}$ concentrations $\left(\mu \mathrm{g} \mathrm{m}^{-3}\right)$ at USA-W, USA-E and Europe. The mean seasonal values are averaged over the period 1987-2014.

\begin{tabular}{lcccccc}
\hline & \multicolumn{2}{c}{ USA-W } & \multicolumn{2}{c}{ USA-E } & \multicolumn{2}{c}{ Europe } \\
& DJF & JJA & DJF & JJA & DJF & JJA \\
\hline $\mathrm{SO}_{2}$ concentration & & & & & & \\
\hline Mean (obs) & 0.71 & 0.45 & 9.83 & 4.17 & 5.00 & 2.10 \\
Mean (model) & 7.39 & 6.32 & 22.18 & 22.93 & 15.34 & 8.08 \\
Bias & 6.69 & 5.87 & 12.34 & 18.76 & 10.34 & 5.99 \\
NMB & 12.16 & 12.85 & 1.37 & 5.01 & 2.64 & 3.09 \\
\hline SO ${ }_{4}^{2-}$ concentration & & & & & & \\
\hline Mean (obs) & 0.48 & 0.95 & 2.71 & 6.51 & 2.81 & 2.85 \\
Mean (model) & 1.23 & 1.21 & 1.88 & 5.15 & 1.72 & 2.50 \\
Bias & 0.75 & 0.25 & -0.83 & -1.35 & -1.09 & -0.35 \\
NMB & 1.63 & 0.26 & -0.32 & -0.22 & -0.38 & -0.13 \\
\hline
\end{tabular}


USA-E UKESM1 does not capture the seasonal cycle in surface $\mathrm{SO}_{2}$ concentrations due to the relatively large model bias in JJA, where the modelled $\mathrm{SO}_{2}$ concentrations are over five times the observed values. In contrast the model over-predicts surface $\mathrm{SO}_{2}$ concentrations in DJF by a factor of 2.3. In USA-W the modelled and observed surface $\mathrm{SO}_{2}$ concentrations are slightly higher in DJF compared with JJA. The model bias is also larger in DJF compared with JJA, but the $\mathrm{SO}_{2}$ concentrations are over-predicted to such a large degree in this region that it is difficult to determine if there is any seasonality in this bias.

UKESM1 clearly captures the seasonal cycle in surface $\mathrm{SO}_{4}^{2-}$ concentration over USA-E, simulating the highest values in summer and the lowest values in winter. The model under-predicts surface $\mathrm{SO}_{4}^{2-}$ concentration by a factor of 0.7 to 0.8 reasonably consistently throughout the seasonal cycle. In the cleaner USA-W region, UKESM1 is able to capture the seasonal cycle in surface $\mathrm{SO}_{4}^{2-}$ concentrations, with the exception of DJF where the model over-predicts surface $\mathrm{SO}_{4}^{2-}$ concentrations by a factor of 2.5. In Europe the observed seasonal cycle in surface $\mathrm{SO}_{4}^{2-}$ concentration has only a small amplitude with mean values of $2.81 \mu \mathrm{g} \mathrm{m}^{-3}$ and $2.85 \mu \mathrm{g} \mathrm{m}^{-3}$ in DJF and JJA respectively.

\subsection{Evaluation of total column $\mathrm{SO}_{2}$ in UKESM1 against satellite observations}

Table 6. Statistics between model runs and $\mathrm{OMI} \mathrm{TCSO}_{2}$ monthly zonally averaged (median) time series (2005-2014) for three latitude bands USA $\left(60-130^{\circ} \mathrm{W}, 25-50^{\circ} \mathrm{N}\right)$; Europe $\left(15^{\circ} \mathrm{W}-40^{\circ} \mathrm{E}, 35-65^{\circ} \mathrm{N}\right)$; South to North East Asia $\left(75-125^{\circ} \mathrm{W}, 20-45^{\circ} \mathrm{N}\right)$. The metrics include the mean bias (MB, DU), root mean square error (RMSE, DU), percentage mean bias (MB\%) and correlation (R).

\begin{tabular}{lcccccc}
\hline & \multicolumn{2}{c}{ USA } & \multicolumn{2}{c}{ Europe } & \multicolumn{2}{c}{ South to North East Asia } \\
Statistic & UKESM1 & UKESM1-SO2 & UKESM1 & UKESM1-SO2 & UKESM1 & UKESM1-SO2 \\
\hline MB & 0.029 & 0.014 & 0.050 & 0.027 & 0.120 & 0.068 \\
RMSE & 0.032 & 0.018 & 0.061 & 0.040 & 0.122 & 0.070 \\
MB\% & 117 & 56 & 110 & 59 & 402 & 228 \\
R & 0.26 & 0.19 & 0.54 & 0.53 & 0.64 & 0.48 \\
\hline
\end{tabular}

Figure 8 shows total column $\mathrm{SO}_{2}\left(\mathrm{TCSO}_{2}\right)$ from UKESM1 and OMI, and the difference between them for DJF and JJA. Note that the quality control for solar zenith angle results in no data availability above $65^{\circ} \mathrm{N}$ degrees or below $65^{\circ} \mathrm{S}$ in the winter months and due to OMI's weaker sensitivity to retrieving $\mathrm{SO}_{2}$ in remote regions we focus on comparing $\mathrm{TCSO}_{2}$ over source and outflow regions ( $\mathrm{Li}$ et al., 2020). Figures 8 a-d show that UKESM1 and OMI broadly agree on the location of the main northern hemisphere $(\mathrm{NH})$ source regions including China, India, Europe and the USA. The model and satellite data both show seasonal cycles in $\mathrm{TCSO}_{2}$ over the large source regions with higher values being modelled and observed during the winter months. However, Figures $8 \mathrm{e}$ and $\mathrm{f}$ show that the UKESM1 $\mathrm{TCSO}_{2}$ values were generally larger than the OMI $\mathrm{TCSO}_{2}$ values in these source regions by $0.6-1.0$ Dobson Units (DU). Over the background regions UKESM1 over-predicts 

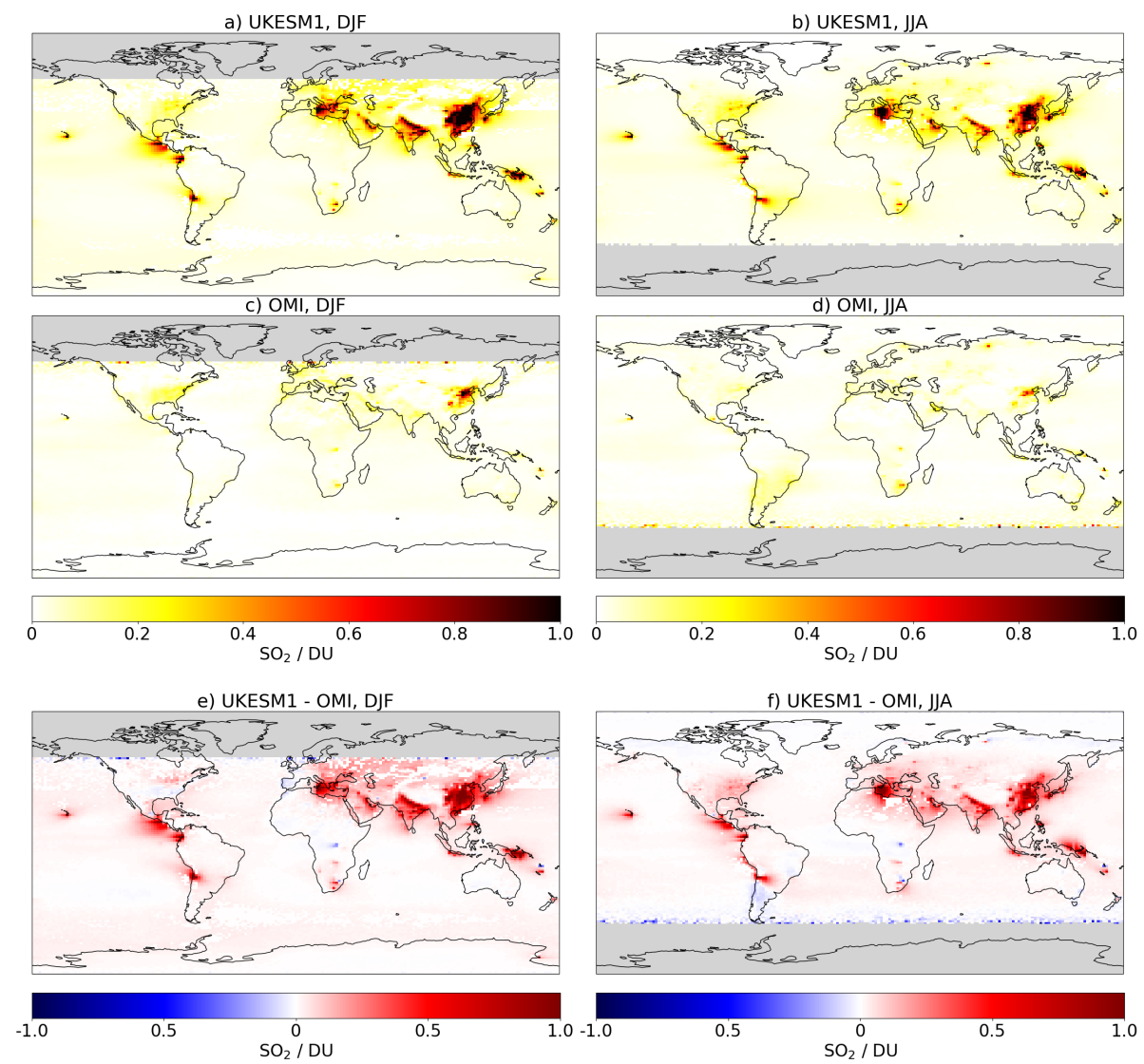

Figure 8. Median Total Column $\mathrm{SO}_{2}$ (Dobson Units) for 2005 to 2014 for UKESM1 (a, b) OMI (c, d) and UKESM1 - OMI (e, f). DJF is shown in the left column and JJA is shown in the right column.

$\mathrm{TCSO}_{2}$ values by $0.2-0.5 \mathrm{DU}$. UKESM1 also has larger volcanic sources and associated outflow, which can be seen over central America, Sicily, Hawaii and Papua New Guinea, for example. This is likely due to the climatology that UKESM1 uses for continuously degassing volcanoes. In agreement with the ground based observations, the satellite data shows an East-West divide in the USA, with greater $\mathrm{TCSO}_{2}$ over USA-E compared with USA-W.

Figure 9 shows modelled and observed $\mathrm{TCSO}_{2}$ over the period from 2005 to 2014 for three source regions, the USA $\left(60-30^{\circ} \mathrm{W}, 25-50^{\circ} \mathrm{N}\right)$, Europe $\left(15^{\circ} \mathrm{E}-40^{\circ} \mathrm{E}, 35-65^{\circ} \mathrm{N}\right)$ and South to North East (SNE) Asia $\left(75-125^{\circ} \mathrm{E}, 20-45^{\circ} \mathrm{W}\right)$. Overall, we find that the observed $\mathrm{TCSO}_{2}$ is reasonably stable over this period in all three regions and that there are clear seasonal cycles showing peak $\mathrm{TCSO}_{2}$ during the $\mathrm{NH}$ winter in the USA and Europe, and slightly earlier in SNE Asia. However, Figures 9a and $\mathrm{b}$ show that modelled $\mathrm{TCSO}_{2}$ decreases over the USA and Europe from 2005-2010 with UKESM1 over-predicting $\mathrm{TCSO}_{2}$ by up to $0.1 \mathrm{DU}$ at the start of the time series. After 2011, UKESM1 is in much better agreement with the observed $\mathrm{TCSO}_{2}$ over both regions. Figure 9c shows that UKESM1 consistently over-predicts $\mathrm{TCSO}_{2}$ over SNE Asia by $1.5-2.0 \mathrm{DU}$ 


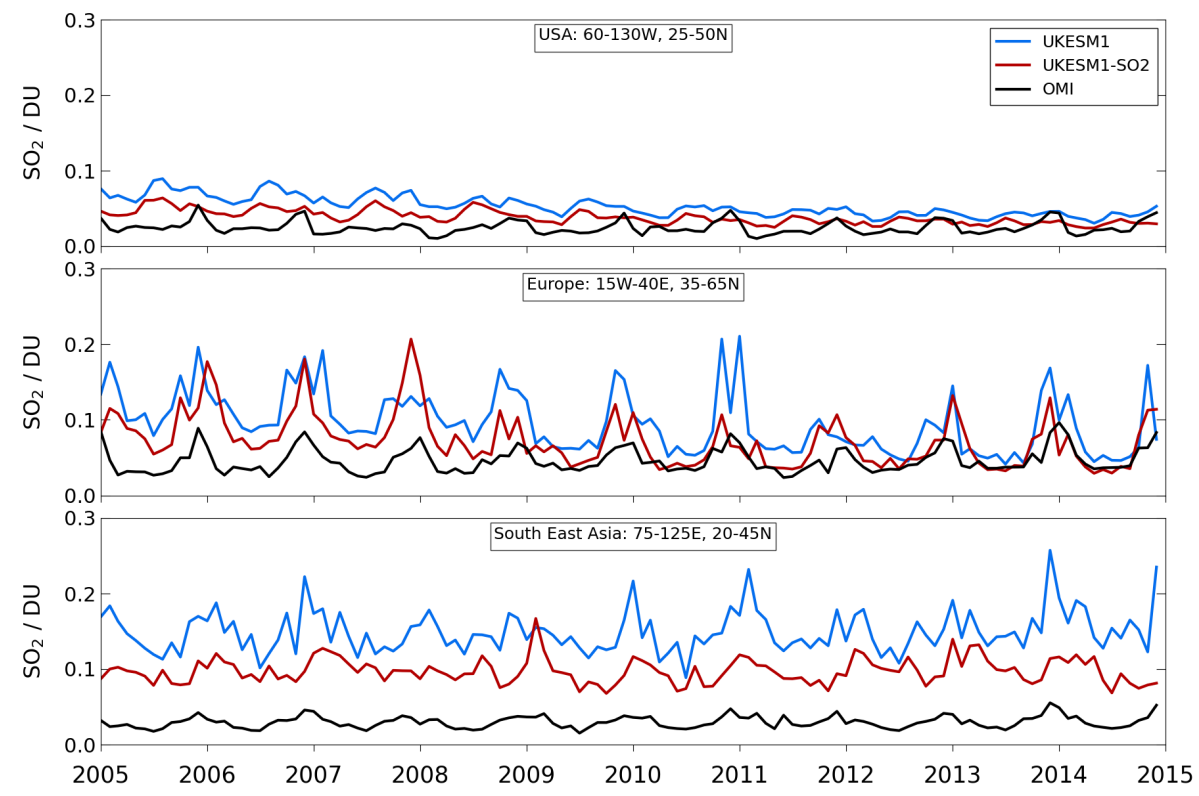

Figure 9. Median Total Column $\mathrm{SO}_{2}$ (Dobson Units) for 2005 to 2014 for USA, (a); Europe, (b); and South to North East Asia, (c).

during the period from 2005 to 2014. UKESM1 does simulate a seasonal cycle in $\mathrm{TCSO}_{2}$ in all three regions. In Europe, UKESM1 is able to predict the peak winter time $\mathrm{TCSO}_{2}$ values, although between 2005-2010 the model has a positive bias of up to 0.1 DU. However, in the USA and to a lesser extent in SNE Asia (Figures 9 a and c respectively), UKESM1 mis-times the peak $\mathrm{TCSO}_{2}$ values. In the USA the model simulates the highest values in the summer rather than in winter, and in SNE Asia the modelled peak $\mathrm{TCSO}_{2}$ values appear shifted several months earlier in relation to the observations.

The observations of $\mathrm{TCSO}_{2}$ and surface $\mathrm{SO}_{2}$ concentrations over Europe both show the impact of emission control policies on keeping atmospheric $\mathrm{SO}_{2}$ levels low and stable (see Figures 2c and 9b). For the USA, we investigate the surface $\mathrm{SO}_{2}$ concentrations separately over the USA-E and USA-W regions, whereas the $\mathrm{TCSO}_{2}$ is averaged over the whole continental USA. As a result, the trend for decreasing surface $\mathrm{SO}_{2}$ concentrations in USA-E (see Figure $2 \mathrm{~b}$ ) is not seen in $\mathrm{TCSO}_{2}$. Using a mean $\mathrm{TCSO}_{2}$ for the continental USA as a whole also results in lower values relative to Europe. This is in contrast to the ground-based observations where surface $\mathrm{SO}_{2}$ concentrations over Europe are intermediate between USA-E and USA-W for the period 2005-2014. The relatively high $\mathrm{TCSO}_{2}$ over Europe is also due to the inclusion of a number of large eastern European sources which are not well represented in the ground based observations. We find that the $\mathrm{TCSO}_{2}$ and surface $\mathrm{SO}_{2}$ concentration observations both agree on the seasonal cycle, showing higher values in winter compared with the summer.

UKESM1 over-predicts surface $\mathrm{SO}_{2}$ concentration to a greater extent than $\mathrm{TCSO}_{2}$ for the USA and Europe. The model over-predicts surface $\mathrm{SO}_{2}$ concentration by a factor of 2.2 - 11.6 for USA-E and USA-W, and 2.4 for Europe compared with 
values of 1.2 (USA) and 1.1 (Europe) for modelled $\mathrm{TCSO}_{2}$ (see Tables 3 and 6). However, the R values for surface $\mathrm{SO}_{2}$ concentration $(>0.8)$ are much better than those for $\mathrm{TCSO}_{2}(0.26-0.53)$, particularly over the USA. The low R value for the USA reflects the poor seasonal agreement in $\mathrm{TCSO}_{2}$ in this region. The comparison against both observational data sets shows that the modelled atmospheric $\mathrm{SO}_{2}$ is too high, both at the surface and through the column. In addition, UKESM1 predicts trends in $\mathrm{TCSO}_{2}$ and surface $\mathrm{SO}_{2}$, particularly prior to 2010, that with the exception of USA-E are not seen in the observations. Both observational data sets also show that UKESM1's over-prediction of atmospheric $\mathrm{SO}_{2}$ is greater in the winter months compared to the summer months over the large source regions, with exceptions in USA-E and the Iberian peninsular (see Figures 9e and f). In USA-E the comparison against the observational data sets shows that UKESM1 fails to capture the seasonal cycle in atmospheric $\mathrm{SO}_{2}$, with the model simulating values that are too high in JJA compared to DJF. In the southern USA-E region and the Iberian peninsular we see that UKESM1 actually under-predicts $\mathrm{TCSO}_{2}$ by up to $0.1 \mathrm{DU}$ in DJF, which does not occur in the comparison with surface $\mathrm{SO}_{2}$ concentrations, even if the model and observations are compared at individual CASTNet and EMEP sites.

\section{Impact of changes to the $\mathrm{SO}_{2}$ dry deposition parameterization in UKESM1}

\subsection{Global scale impacts}

Figure 10 shows the impact of the modified $\mathrm{SO}_{2}$ dry deposition parameterization on global $\mathrm{SO}_{2}$ dry deposition, surface $\mathrm{SO}_{2}$ and $\mathrm{SO}_{4}^{2-}$ concentrations for the period 1987-2014. Figures $10 \mathrm{~b}$ and c show that the changes to the $\mathrm{SO}_{2}$ dry deposition parameterization are behaving as expected by increasing $\mathrm{SO}_{2}$ dry deposition. The largest absolute increases of up to $3 \times 10^{-3} \mathrm{~kg} \mathrm{~m}^{-2} \mathrm{y}^{-1}$ occur over the main source regions of USA-E, eastern China, and central and eastern Europe (Figure 10b). However, Figure 10c shows that the largest relative changes in dry deposition are over the ocean, with $\mathrm{SO}_{2}$ dry deposition increasing up to $100 \%$ in the southern ocean. Over other ocean areas, the increase was $20-80 \%$. Although the absolute changes over the ocean are small $\left(<1 \times 10^{-5} \mathrm{~kg} \mathrm{~m}^{-2} \mathrm{y}^{-1}\right)$, the large global surface area of ocean means that this increase is important for the global sulphur cycle. In UKESM1-SO2 $\mathrm{R}_{\text {surf }}$-mod increases the length of time land surfaces remain wet after rainfall, thus increasing $\mathrm{SO}_{2}$ dry deposition over land surfaces (as seen in Figures 10b) due to the high solubility of $\mathrm{SO}_{2}$ in water. Note that $\mathrm{R}_{\text {surf }}$-mod also makes $\mathrm{SO}_{2}$ dry deposition a function of the soil moisture content and this aspect of this change drives decreases in $\mathrm{SO}_{2}$ dry deposition of 20-40\% over desert regions, such as the Sahara (see Figures 10c). Conversely $\mathrm{R}_{\text {surf }}$-mod does not impact ocean surfaces and the increases in $\mathrm{SO}_{2}$ dry deposition over oceans seen in Figures 10c are driven by $R_{\text {water }}-$ mod.

The largest absolute reductions in mean annual surface $\mathrm{SO}_{2}$ and $\mathrm{SO}_{4}^{2-}$ concentrations are over the source regions, corresponding with the locations of the largest increases in $\mathrm{SO}_{2}$ dry deposition. This is expected because dry deposition of $\mathrm{SO}_{2}$ to the surface is directly proportional to the surface concentration (Equation 1). Figure 10e shows that mean annual surface $\mathrm{SO}_{2}$ concentration was reduced by up to $20 \mu \mathrm{g} \mathrm{m}^{-3}$ in the eastern USA, eastern China, and central and eastern Europe, which 

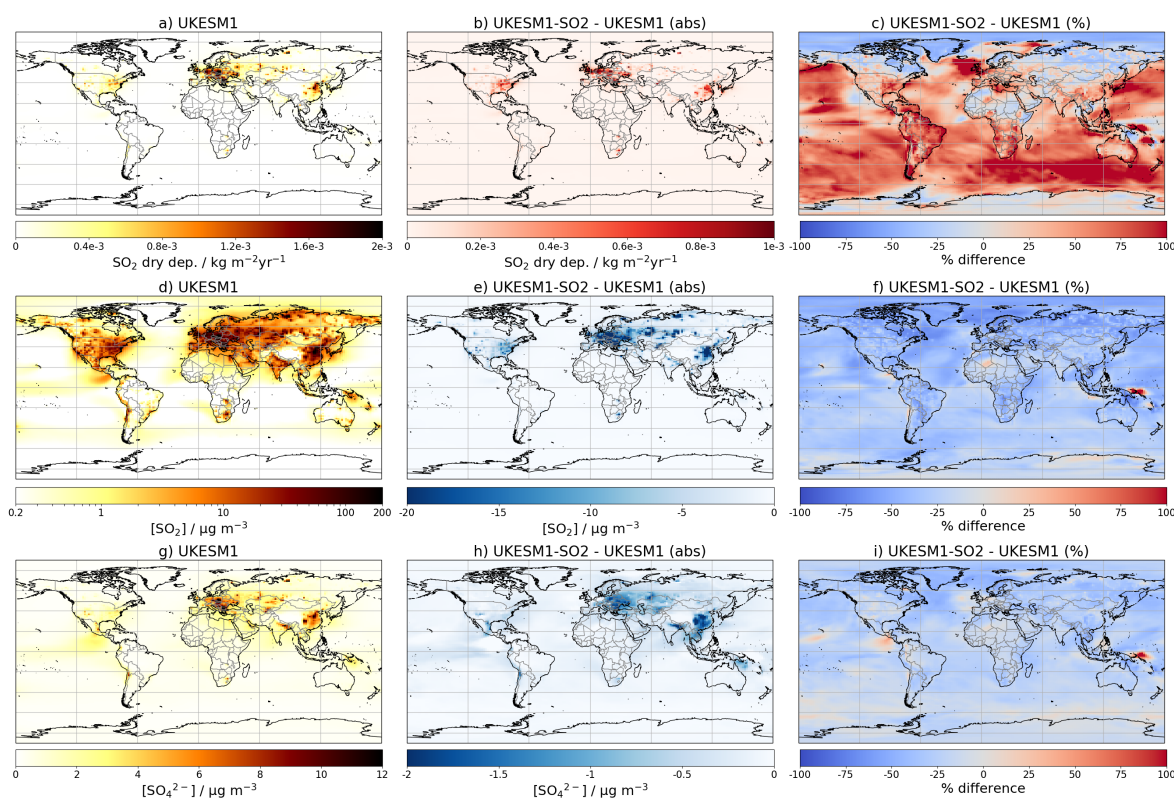

f) UKESM1-SO2 - UKESM1 (\%)
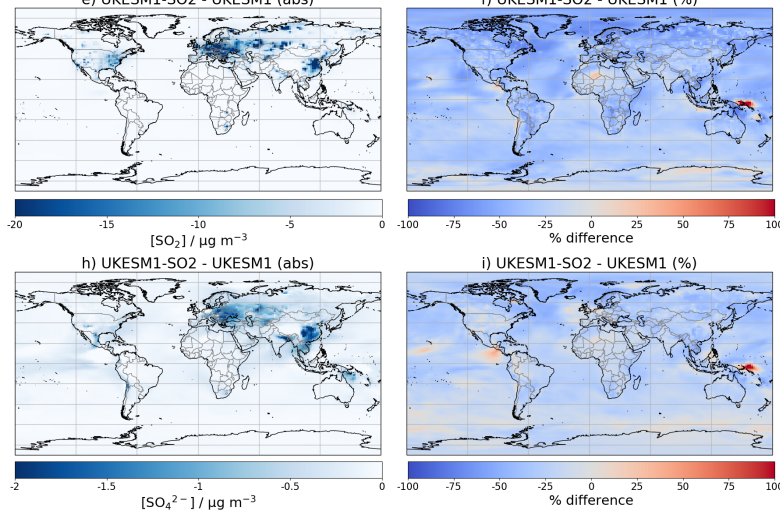

Figure 10. $\mathrm{SO}_{2}$ dry deposition, (a-c); surface $\mathrm{SO}_{2}$ concentration, (d-f) and surface $\mathrm{SO}_{4}^{2-}$ concentration (g-i) for UKESM1 (left column), absolute difference for UKESM1-SO2 - UKESM1 (middle column) and percentage difference for UKESM1-SO2 - UKESM1 (right column). Each plot shows mean data for the period 1987-2014.

corresponds to a percentage decrease of $30-50 \%$. Note that this is similar to the percentage decrease in mean annual surface $\mathrm{SO}_{2}$ concentration over remote and ocean regions, although the absolute fluxes are much larger over the source regions. With the exception of some areas in the Sahara and the Middle East, we do not see increases in mean annual surface $\mathrm{SO}_{2}$ concentration where dry deposition fluxes decrease (albeit by very low amounts), such as the Arctic. We suggest that this is because these areas are remote and contain no $\mathrm{SO}_{2}$ sources and by reducing $\mathrm{SO}_{2}$ in the source regions, we reduce overall atmospheric $\mathrm{SO}_{2}$ loading and less is transported to remote areas. Figures $10 \mathrm{~h}$ and i show that mean annual surface $\mathrm{SO}_{4}^{2-}$ concentrations are also reduced over the main source regions, although the reductions over the USA are relatively small compared to the other large source regions ( $0.5 \mu \mathrm{g} \mathrm{m}^{-3}$ compared with up to $3 \mu \mathrm{g} \mathrm{m}^{-3}$ in central and eastern Europe and China). Proportionally, the reduction in mean annual surface $\mathrm{SO}_{4}^{2-}$ concentration is smaller than that for mean annual $\mathrm{SO}_{2}$ concentration, with decreases generally less than $5 \%$ over most source regions.

\subsection{Evaluation of UKESM1-SO2 against ground-based observations}

In Figure 11 and Table 7 we evaluate UKESM1-SO2 against the ground-based observations of mean annual surface $\mathrm{SO}_{2}$ and

$\mathrm{SO}_{4}^{2-}$ concentration for the USA and Europe regions over the period from 1987-2014. UKESM1-SO2 is also evaluated against $\mathrm{SO}_{2}$ dry deposition flux from CASTNet over the same period. Figures $11 \mathrm{a}$ and $\mathrm{b}$ show that $\mathrm{SO}_{2}$ dry deposition flux is increased 

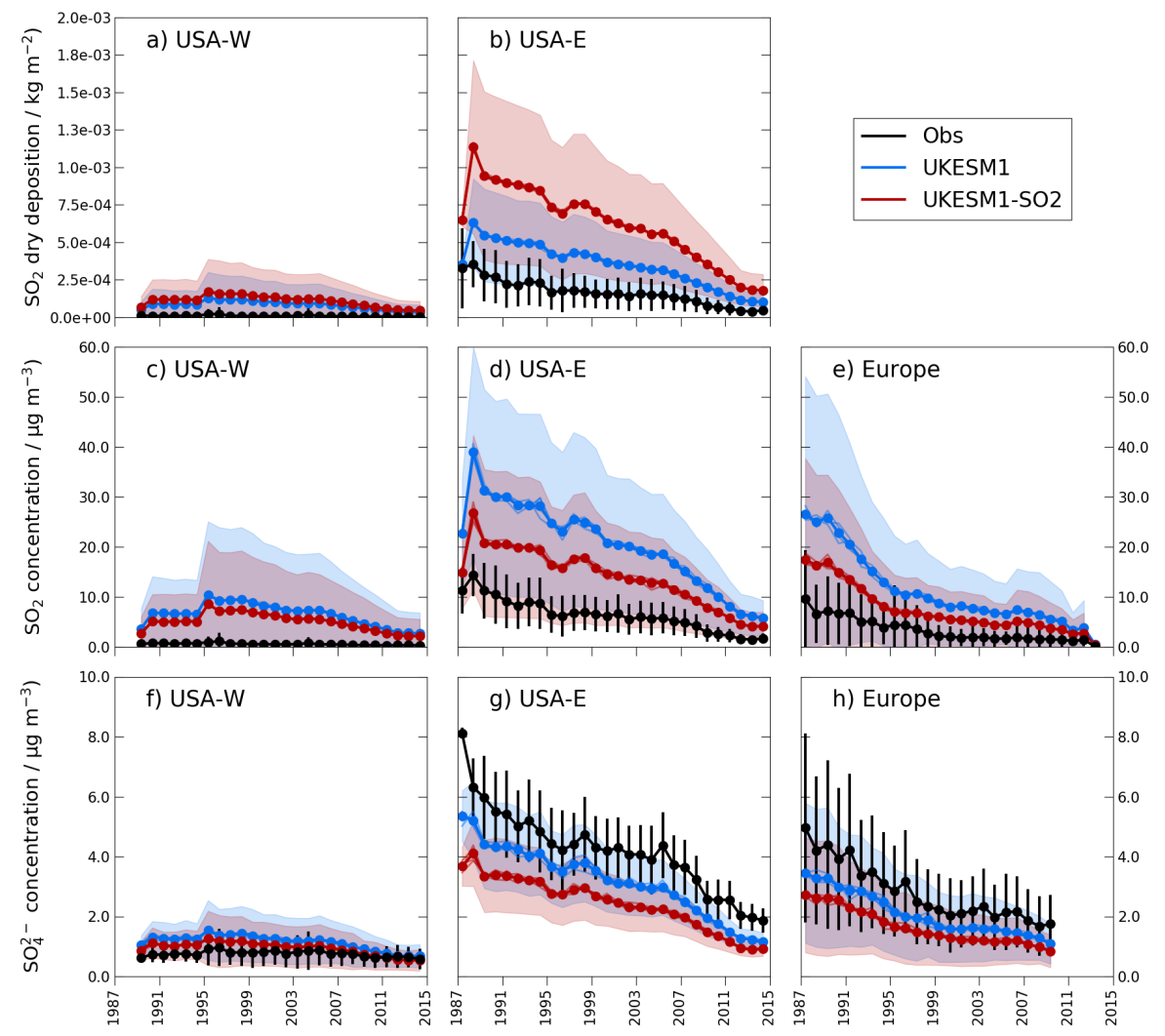

Figure 11. Time series of observed and modelled mean annual $\mathrm{SO}_{2}$ dry deposition flux (top row), surface $\mathrm{SO}_{2}$ concentration (middle row) and $\mathrm{SO}_{4}^{2-}$ concentration (bottom row) for USA-W, (a, c, f); USA-E, (b, d, g) and Europe (e, h). No $\mathrm{SO}_{2}$ dry deposition flux observations are available for Europe.

in UKESM1-SO2 relative to UKESM1 with this increase being more pronounced over USA-E compared with USA-W (see also Table 7). The increase in $\mathrm{SO}_{2}$ dry deposition in UKESM1-SO2 does enhance the model's over-prediction of this parameter relative to the CASTNet data, with NMB increasing from 1.15 in UKESM1 to 3.0 in UKESM1-SO2. Mean annual $\mathrm{SO}_{2}$ dry deposition fluxes are very low over USA-W due to the much lower concentrations of $\mathrm{SO}_{2}$ in this region. UKESM1 does over-predict mean annual $\mathrm{SO}_{2}$ dry deposition flux in this region too, but the absolute bias changes very little in UKESM1-SO2 (see Table 7). Figures $11 \mathrm{c}$ - e show that model bias in mean annual surface $\mathrm{SO}_{2}$ concentration is reduced in UKESM1-SO2 compared with UKESM1 in all three regions over the period 1987-2014. The largest absolute reduction is in USA-E where mean annual surface $\mathrm{SO}_{2}$ concentration decreases from $20.36 \mu \mathrm{g} \mathrm{m}^{-3}$ to $13.97 \mu \mathrm{g} \mathrm{m}^{-3}$, however, the largest reduction in NMB is in USA-W where it decreases from 11.57 to 8.77 (see Table 7). The model's over prediction of mean annual surface $\mathrm{SO}_{4}^{2-}$ concentration is reduced over USA-W in UKESM1-SO2 compared with UKESM1, with NMB decreasing from 0.5 to 0.24. However, the model's under prediction of mean annual surface $\mathrm{SO}_{4}^{2-}$ concentration over USA-E and Europe increases, with 
Table 7. Statistics for mean annual surface $\mathrm{SO}_{2}$ and $\mathrm{SO}_{4}^{2-}$ concentrations and $\mathrm{SO}_{2}$ dry deposition flux for UKESM1 and UKESM1-SO2. The mean seasonal values are averaged over the period 1987-2014 and the time slice mean is in $\mu \mathrm{g} \mathrm{m}^{-3}$ for $\mathrm{SO}_{2}$ and $\mathrm{SO}_{4}^{2-}$ concentrations, and $\mathrm{kg} \mathrm{m}^{-2} \mathrm{y}^{-1}$ for $\mathrm{SO}_{2}$ dry deposition flux.

\begin{tabular}{|c|c|c|c|c|c|c|}
\hline & \multicolumn{2}{|c|}{ USA-W } & \multicolumn{2}{|c|}{ USA-E } & \multicolumn{2}{|c|}{ Europe } \\
\hline & UKESM1 & UKESM1-SO2 & UKESM1 & UKESM1-SO2 & UKESM1 & UKESM1-SO2 \\
\hline \multicolumn{7}{|c|}{$\mathrm{SO}_{2}$ dry deposition } \\
\hline Mean (obs) & $7.67 \times 10^{-6}$ & - & $1.62 \times 10^{-4}$ & - & - & - \\
\hline Mean & $8.11 \times 10^{-5}$ & $1.09 \times 10^{-4}$ & $3.48 \times 10^{-4}$ & $6.13 \times 10^{-4}$ & - & - \\
\hline Bias & $7.34 \times 10^{-5}$ & $1.01 \times 10^{-4}$ & $1.86 \times 10^{-4}$ & $4.51 \times 10^{-4}$ & - & - \\
\hline NMB & 10.83 & 14.85 & 1.15 & 3.00 & - & - \\
\hline \multicolumn{7}{|c|}{$\mathrm{SO}_{2}$ concentration } \\
\hline Mean (obs) & 0.53 & - & 6.31 & - & 3.29 & - \\
\hline Mean (model) & 6.45 & 5.00 & 20.36 & 13.97 & 11.12 & 7.30 \\
\hline Bias & 5.92 & 4.48 & 14.06 & 7.67 & 7.83 & 4.01 \\
\hline NMB & 11.57 & 8.77 & 2.23 & 1.35 & 2.38 & 1.49 \\
\hline \multicolumn{7}{|c|}{$\mathrm{SO}_{4}^{2-}$ concentration } \\
\hline Mean (obs) & 0.74 & - & 4.19 & - & 2.82 & - \\
\hline Mean & 1.14 & 0.94 & 3.17 & 2.43 & 2.09 & 1.64 \\
\hline Bias & 0.38 & 0.19 & -1.03 & -1.76 & -0.73 & -1.18 \\
\hline NMB & 0.5 & 0.24 & -0.24 & -0.43 & -0.26 & -0.42 \\
\hline
\end{tabular}

$\mathrm{NMB}=0.25$ in UKESM1 and NMB $=0.43$ in UKESM1-SO2 (see Table 7). We find that the changes to the surface concentration and dry deposition flux occur almost uniformly over the seasonal cycle and so do not change the patterns in seasonal bias that are described in Section 3.4 for surface $\mathrm{SO}_{2}$ and $\mathrm{SO}_{4}^{2-}$ concentrations.

\subsection{Evaluation of UKESM1-SO2 against $\mathrm{TCSO}_{2}$ observations}

The impact of the modifications to the $\mathrm{SO}_{2}$ dry deposition parameterization on $\mathrm{TCSO}_{2}$ are shown in Figure 12 and Table 6. Figures $12 \mathrm{a}$ and $\mathrm{b}$ show that $\mathrm{TCSO}_{2}$ over the source regions is lower in UKESM1-SO2 relative to UKESM1 by $0.1-0.5 \mathrm{DU}$ in

DJF and JJA. This results in UKESM1-SO2 having a smaller positive bias in $\mathrm{TCSO}_{2}$ compared with that of UKESM. Figures $12 \mathrm{c}$ and $\mathrm{d}$ show that UKESM1-SO2-OMI is $0.3-0.5 \mathrm{DU}$ over source regions compared to $0.6-1.0 \mathrm{DU}$ for UKESM1 - OMI (see Section 3.5, Figure 8). This represents a decrease in the global $\mathrm{TCSO}_{2}$ model - OMI bias of 20-30\%. Over the outflow 

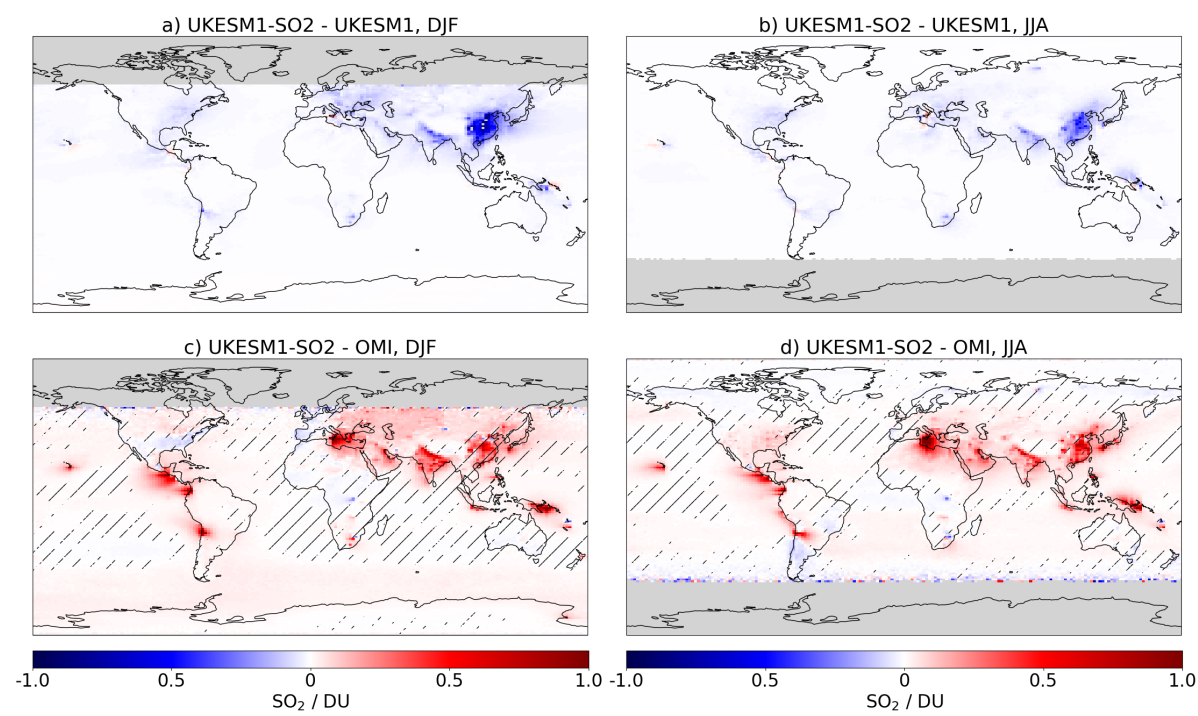

Figure 12. Difference in $\mathrm{TCSO}_{2}$ between UKESM1 and UKESM-SO2 for DJF (a) and JJA (b). Difference in TCSO 2 between UKESM1SO2 and OMI for DJF (c) and JJA (d).

regions (e.g. off the USA eastern seaboard), $\mathrm{TCSO}_{2}$ has reduced by $30-50 \%$ and over the source regions, this varies by $30-50 \%$ for South to North East Asia, 20-30\% for Europe and 10-30\% for the USA (see Table 6). However, Figures 12c and d also show that the inter-model differences are smaller than the existing model-satellite difference, i.e. the hatched regions are sporadic with limited coverage.

\section{Discussion}

The evaluation of UKESM1 against ground-based observations of $\mathrm{SO}_{2}$ and $\mathrm{SO}_{4}^{2-}$ concentrations from the USA and Europe, as well as $\mathrm{SO}_{2}$ dry deposition fluxes from the USA, shows that the model is able to represent recent historical changes in these variables. UKESM1 is also able to capture the spatial patterns in surface $\mathrm{SO}_{2}$ and $\mathrm{SO}_{4}^{2-}$ concentrations and $\mathrm{SO}_{2}$ dry deposition, simulating larger values close to the sources and lower values away from the sources. However, UKESM1 generally over-predicts surface $\mathrm{SO}_{2}$ concentrations and dry deposition fluxes, while under-predicting surface $\mathrm{SO}_{4}^{2-}$ concentrations over the period 1987-2014. Further, we find that UKESM1 over-predicts the rate at which the surface $\mathrm{SO}_{2}$ concentrations decrease over this period.

We also make use of the updated $\mathrm{TCSO}_{2}$ product from OMI to evaluate UKESM1, finding that the model captures spatial patterns in $\mathrm{TCSO}_{2}$ at the global scale. Importantly, this evaluation allows us to identify model bias in regions without longterm ground-based networks, showing that UKESM1 over-predicts $\mathrm{TCSO}_{2}$ over all source and outflow regions. We find that 
although the ground-based and satellite observations are subject to different uncertainties, UKESM1's relative over-prediction of both surface $\mathrm{SO}_{2}$ concentration and $\mathrm{TCSO}_{2}$ is similar in the USA and Europe. This suggests that our findings of positive bias in modelled atmospheric $\mathrm{SO}_{2}$ is robust. We have also demonstrated that a more realistic treatment of $\mathrm{SO}_{2}$ dry deposition in UKESM1 reduces the model's atmospheric loading of $\mathrm{SO}_{2}$ and $\mathrm{SO}_{4}^{2-}$. However, we find that UKESM1's under-prediction of surface $\mathrm{SO}_{4}^{2-}$ concentrations and over-prediction of $\mathrm{SO}_{2}$ dry deposition fluxes increases when the changes are included in the model, suggesting that there are further uncertainties UKESM1's representation of the complex sulphur cycle processes. Additionally, the spatial and temporal differences in the model bias suggests that the drivers of model bias are regionally and seasonally dependant.

Broadly, model bias in atmospheric $\mathrm{SO}_{2}$ can be driven by too little removal of $\mathrm{SO}_{2}$ from the atmosphere (via deposition or oxidation) or too high emissions. UKESM1 uses $\mathrm{SO}_{2}$ emissions from CMIP6 (Eyring et al., 2016). In comparing these emissions with the HTAP-OMI (Liu et al., 2018) and EDGAR (Crippa et al., 2018) data sets, Pope and Chipperfield (2021) showed that the total $\mathrm{SO}_{2}$ emissions in CMIP6 are moderately larger than the HTAP-OMI and EDGAR data sets. Further, comparing the spatial distribution showed that the CMIP6 emissions from almost all sources are larger than the HTAP-OMI emissions. Exceptions occur at a number of point locations, which are likely from OMI rather than HTAP. Emission injection height is also an important constraint on near surface $\mathrm{SO}_{2}$ concentrations as demonstrated by Yang et al. (2019). This study found that uncertainty in industrial emission height resulted in modeled near-surface $\mathrm{SO}_{2}$ concentrations varying between $70 \%$ and $130 \%$ over most land regions, higher than the overall uncertainty of $8-14 \%$ attributed to $\mathrm{SO}_{2}$ emission rates. The $\mathrm{SO}_{2}$ injection height in UKESM1 was investigated by Mulcahy et al. (2020) who used injection heights prescribed as for HadGEMGC3.1, where 50\% of energy and industry sector emissions are injected in to the atmosphere at a height of $500 \mathrm{~m}$. Mulcahy et al. (2020) showed that the introduction of a vertical profile for $\mathrm{SO}_{2}$ emissions in UKESM1 had negligible impact on surface $\mathrm{SO}_{4}^{2-}$ concentrations at measurement sites in Europe and the USA, suggesting an important role for the aerosol chemistry in these regions. Emitting the $\mathrm{SO}_{2}$ at higher altitudes will act to reduce surface $\mathrm{SO}_{2}$ concentrations and therefore model's bias against surface observations of both $\mathrm{SO}_{2}$ concentration and $\mathrm{SO}_{2}$ dry deposition flux. However, Pope and Chipperfield (2021) showed that model bias in $\mathrm{TCSO}_{2}$ increased when emission injection heights were increased. This finding further suggests that the CMIP6 emissions are too high and that using a vertical profile for the emissions to some extent shifts the model's bias in $\mathrm{SO}_{2}$ to higher altitudes. We suggest that model experiments with different emissions inventories and injection height profiles should be able to cast some light on the role of $\mathrm{SO}_{2}$ emissions in model bias in the sulphur cycle.

The two main removal pathways for $\mathrm{SO}_{2}$ are oxidation to sulphate and dry deposition to the Earth's surface. In this study we have evaluated a more realistic treatment of $\mathrm{SO}_{2}$ dry deposition in UKESM1 that accounts for the high solubility of $\mathrm{SO}_{2}$ in water, finding that it reduces the models' atmospheric loading of $\mathrm{SO}_{2}$. This reduces positive model bias in surface $\mathrm{SO}_{2}$ concentrations in the USA and Europe, and in $\mathrm{TCSO}_{2}$ across most of the globe. The changes have the largest impact over source regions because dry deposition flux is directly proportional to the atmospheric concentration of $\mathrm{SO}_{2}$ (Equation 1). However, while we see a direct reduction in UKESM1's bias in atmospheric $\mathrm{SO}_{2}$ loading, the true impact of the changes to the dry 
deposition parameterization are confounded by model uncertainty in other aspects of the complex sulphur cycle as well as the inherent difficulties associated with evaluating a global model against point observations.

Dry deposition is a highly parameterized process and often poorly represented, particularly in global models. Similarly to UKESM1, Vet et al. (2014) showed that $\mathrm{SO}_{2}$ dry deposition fluxes were over-predicted by the 23 member model ensemble used for the TF-HTAP exercise relative to inferential data sets from measurement networks (including CASTNet). A key uncertainty highlighted in this study was that associated with the inferred dry deposition fluxes; from CASTNet these could be up to $30 \%$ lower than direct observations of $\mathrm{SO}_{2}$ dry deposition flux (Baumgardner et al., 2002). However, the fluxes simulated by UKESM1 are a factor of 2 to 10 higher than the inferred data from USA-E and USA-W, indicating that the modelled deposition fluxes are almost certainly too large. Additional sources of uncertainty in model simulations of $\mathrm{SO}_{2}$ dry deposition may include land surface cover, changes in the atmospheric $\mathrm{SO}_{2}: \mathrm{NH}_{3}$ ratio and the ratio between wet and dry deposition of $\mathrm{SO}_{2}$. Mulcahy et al. (2020) showed that wet deposition, and to a lesser extent dry deposition, of $\mathrm{SO}_{2}$ was considerably lower in UKESM1 compared with HadGEM-GC3.1. Paulot et al. (2017) also report that poor representation of wet deposition likely contributed to bias in modelled surface $\mathrm{SO}_{4}^{2-}$ concentrations. Too low wet deposition would also contribute to the model's over-prediction of surface $\mathrm{SO}_{2}$ concentration. Dry deposition is sensitive to land surface type, which may not be well captured in global models. In this study the UKESM1 configuration uses 13 land cover classes including 11 plant functional types (Archibald et al., 2020). This is reasonable for a global model, but inevitably detail is lost. Vet et al. (2014) also suggest that $\mathrm{SO}_{2}$ dry deposition may depend on the atmospheric $\mathrm{NH}_{3}$ loading. Long term measurements at a UK site showed that $\mathrm{SO}_{2}$ dry deposition velocity has increased with time, which was attributed to changing ratios of $\mathrm{SO}_{2}: \mathrm{NH}_{3}$ as $\mathrm{SO}_{2}$ concentrations have decreased faster than $\mathrm{NH}_{3}$ concentrations (Vet et al., 2014; Fowler et al., 2009). Currently nitrate chemistry is not represented in UKESM1, although it is planned for future model versions, and $\mathrm{NH}_{3}$ has not been evaluated in the model, so it is unknown how these factors may contribute to the model's bias in $\mathrm{SO}_{2}$ dry deposition flux and $\mathrm{SO}_{2}$ concentrations.

The role of uncertainty in sulphur cycle chemistry becomes apparent when we consider UKESM1's bias in surface $\mathrm{SO}_{4}^{2-}$ concentrations in combination with the biases in $\mathrm{SO}_{2}$ concentrations and dry deposition. In Europe and USA-E, UKESM1 under-predicts surface $\mathrm{SO}_{4}^{2-}$ concentrations, despite the large positive biases in $\mathrm{SO}_{2}$ concentrations through much of the period from 1987-2014. Note that there are exceptions close to certain point sources, particularly in Europe. However, in the cleaner USA-W region surface $\mathrm{SO}_{4}^{2-}$ concentrations are consistently over-predicted. We suggest that in USA-W too high $\mathrm{SO}_{2}$ emissions, possibly in combination with too low emission heights and the associated biases in dry deposition, drive the model's over-prediction of surface $\mathrm{SO}_{4}^{2-}$ concentrations in this region. However, In the polluted regions of Europe and USA-E the under-prediction of surface $\mathrm{SO}_{4}^{2-}$ concentrations, despite large over-predictions of surface $\mathrm{SO}_{2}$ concentrations suggests that sulphur cycle chemistry is not correctly represented there. In addition, UKESM1 is known to under-predict surface $\mathrm{O}_{3}$ concentrations (Archibald et al., 2020). Mulcahy et al. (2020) showed that there are global and regional differences in oxidant concentrations and in the $\mathrm{SO}_{2}$ lifetime between UKESM1 and the HadGEMGC3.1 model, with the latter better able to capture surface $\mathrm{SO}_{4}^{2-}$ concentrations. This highlights the requirement for a more detailed investigation of $\mathrm{SO}_{2}$ oxidation in UKESM1, 
particularly in polluted regions.

Further, uncertainty in UKESM1's sulphur chemistry appears to be seasonally dependant. In USA-E and Europe UKESM1 over-predicts $\mathrm{SO}_{2}$ (surface concentration and $\mathrm{TCSO}_{2}$ ) and under-predicts surface $\mathrm{SO}_{4}^{2-}$ at all times of the year, but there is seasonal variation in these biases. In Europe, the model bias is largest in DJF which drives a stronger seasonal cycle relative to the observations. This is in agreement with Turnock et al. (2015) who investigated $\mathrm{SO}_{4}^{2-}$ in an earlier HadGEM3-UKCA configuration. The seasonality in UKESM1's bias over Europe may be due to the model under-predicting in-cloud $\mathrm{SO}_{2}$ oxidation via $\mathrm{O}_{3}$ (Table 1). In winter and at higher latitudes this reaction is likely to be the dominant removal pathway due to lower availability of $\mathrm{H}_{2} \mathrm{O}_{2}$ (Turnock et al., 2019). However, the picture is different in USA-E, where UKESM1 over-predicts $\mathrm{SO}_{2}$ to a larger extent in JJA compared with DJF and there is little seasonality in the model's under-prediction $\mathrm{SO}_{4}^{2-}$. In USA-E it is likely that uncertainty in UKESM1's representation of $\mathrm{SO}_{2}$ oxidation via both $\mathrm{O}_{3}$ and $\mathrm{H}_{2} \mathrm{O}_{2}$ (Table 1) contributes to the bias in $\mathrm{SO}_{2}$ and $\mathrm{SO}_{4}^{2-}$ as the higher average latitude of the USA-E sites mean that the $\mathrm{O}_{3}$ oxidation pathway is less important in this region and Paulot et al. (2017) showed that $\mathrm{SO}_{4}^{2-}$ concentrations are sensitive to both pathways in winter. From this study it is not clear what is driving the relatively large positive bias in $\mathrm{SO}_{2}$ in JJA over USA-E and we stress the need for closer examination of the sulphur chemistry in UKESM1.

Recent studies have also shown that cloud water $\mathrm{pH}$ may be an important factor in the aqueous phase oxidation of $\mathrm{SO}_{2}$ to $\mathrm{SO}_{4}^{2-}$ (Turnock et al., 2019). While a temporally and spatially uniform cloud $\mathrm{pH}$ of 5 is currently used in UKESM1, observations of this quantity show that it varies in space and time. Observations at an American site showed that mean cloud $\mathrm{pH}$ increased from 4 to 4.8 between 1994 and 2014 (Schwab et al., 2016); at Mt Tai in North China values of cloud pH measured in 2007-2008 were between 3.56 and 7.64 and measurement campaigns between 1985 and 2008 at various European, North American and East Asian locations reported values between 3.34 and 5.29 (Guo et al., 2012). Turnock et al. (2019) showed that varying this value in the HadGEM3-UKCA model can have a large impact on $\mathrm{SO}_{2}$ and $\mathrm{SO}_{4}^{2-}$ concentrations. Over source regions, including Europe and North America, increasing the cloud water $\mathrm{pH}$ by 1.0 reduced the annual mean global $\mathrm{SO}_{2}$ column burden by approximately $50 \%$ as more $\mathrm{SO}_{2}$ was oxidized in cloud droplets, and consequently there were small increases in the annual mean sulphate column burden over these regions. Conversely, outside of polluted regions increasing the cloud water $\mathrm{pH}$ reduced the sulphate column burden by $10 \%$ to $40 \%$ globally. These results indicate that having a more realistic treatment of cloud water $\mathrm{pH}$ could reduce UKESM1's biases in $\mathrm{TCSO}_{2}$, and potentially in $\mathrm{SO}_{2}$ and $\mathrm{SO}_{4}^{2-}$ concentrations remote from source regions. However, is unlikely to be a dominant removal pathway at the surface and any impact on surface $\mathrm{SO}_{2}$ concentrations, especially close to sources would be expected to be minimal.

In an Earth system model such as UKESM1, there are inevitably some compromises in the complexity of the chemistry and aerosol scheme as these are computationally expensive. While the sulphur chemistry represented in the UKCA-StratTrop model used in UKESM1 accounts for important $\mathrm{SO}_{2}$ and DMS oxidation reactions, as well as simulating oxidants (rather than the offline oxidant scheme used in HadGEM-GC3.1) it cannot be complete. In the recently developed CRI-Strat scheme the 
sulphur chemistry reactions are as for UKCA-STratTrop, but there is a more comprehensive treatment of non-methane volatile compounds (NMVOC) (Archer-Nicholls et al., 2020) resulting in higher surface ozone concentrations, particularly over polluted areas in summer, compared with UKCA-StratTrop. As demonstrated by Mulcahy et al. (2020) the increased oxidants in UKESM1 relative to HadGEM-GC3.1 likely contribute to reducing the $\mathrm{SO}_{2}$ lifetime from 4.29 to 3.86 days. CRI-Strat is able to be used in UKESM1 and the higher oxidant loading may reduce $\mathrm{SO}_{2}$ oxidation lifetime further with a concurrent increase in $\mathrm{SO}_{4}^{2-}$. The impact of more detailed DMS oxidation chemistry was investigated by Revell et al. (2019) who found that surface $\mathrm{SO}_{2}$ concentrations increased, possibly due to including reactions of DMS with halogen species. Revell et al. (2019) also found that $\mathrm{SO}_{4}^{2-}$ concentrations decreased, likely as a result of there being more DMS oxidation reactions. Although Revell et al. (2019)'s results focused on the Southern Ocean, the global impact of using more complex DMS chemistry would be very informative.

Model resolution is also likely to be an important source of model bias in this study. In evaluating UKESM1 against the CASTNet and EMEP data sets we are comparing a simulated value generated from a model grid box approximately 200$300 \mathrm{~km}$ with a point observation. This may be a particular problem for the surface $\mathrm{SO}_{2}$ concentrations and $\mathrm{SO}_{2}$ dry deposition fluxes because in reality a large fraction (20-40\%) of $\mathrm{SO}_{2}$ emitted from point sources is lost in the first $100 \mathrm{~km}$, which is sub-grid scale relative to the model grid boxes (Smith and Jeffrey, 1975; Wys et al., 1978). In UKESM1 all the $\mathrm{SO}_{2}$ is evenly emitted across the grid box and then the deposition is calculated. In reality in large fraction of the emitted $\mathrm{SO}_{2}$ never makes it to the grid scale, driving overall large model biases compared with the ground based observations which are not necessarily close to the point sources. In addition, the model resolution can not capture complex orography, meaning that transport of $\mathrm{SO}_{2}$ may not be well represented. This could be a particular problem in mountainous areas of USA-W VanCuren and Gustin (2015). High resolution model studies would beneficial to address the both importance of orography and to investigate the $\mathrm{SO}_{2}$ losses close to sources. We also suggest that evaluating UKESM1 against chemical re-analysis fields of $\mathrm{SO}_{2}$ could reduce some of the bias that occurs with using using point observations, but there are uncertainties associated with this approach too (Ukhov et al., 2020).

\section{Conclusions}

We evaluate UKESM1 against ground-based and satellite observations of selected sulphur species over the recent historical period. We find that UKESM1 is able to capture the temporal and spatial patterns in surface $\mathrm{SO}_{2}$, surface sulphate concentration, $\mathrm{SO}_{2}$ dry deposition and $\mathrm{TCSO}_{2}$. However, compared to observations we find that the model is biased, depending on the variable, region and species. We address one possible source of bias by introducing a more realistic treatment of $\mathrm{SO}_{2}$ dry deposition, a key loss process for this species. This change reduces model bias in surface $\mathrm{SO}_{2}$ concentrations and $\mathrm{TCSO}_{2}$. However, it is apparent that other biases exits within the complex sulphur cycle and we highlight some key areas for further 
investigation to better understand these and target areas for development.

Our evaluation suggests uncertainty in UKESM1's sulphur chemistry is also an important driver of the biases seen in this study, in particular over polluted regions. Two priorities for further investigation into the oxidation of $\mathrm{SO}_{2}$ in UKESM1 are (i) an evaluation of the CRI-Strat scheme and (ii) a more realistic treatment of cloud water $\mathrm{pH}$. The model's necessarily limited DMS chemistry may also contribute to bias in atmospheric sulphur loading over remote ocean areas. While testing the available, more detailed representations of DMS chemistry in the fully coupled UKESM1 model may not be feasible, their impact at the global scale could be assessed in UKCA. The impact of the nitrate scheme currently in development for UKESM1 will also be investigated in relation to the sulphur cycle. Another aspects of UKESM1's sulphur cycle that would benefit from more detailed analysis is the ratio between wet and dry deposition and how this compares with observations. We also suggest that high resolution studies to investigate $\mathrm{SO}_{2}$ deposition close to sources would be beneficial for a better understanding of these processes. Finally, we suggest that the $\mathrm{SO}_{2}$ emissions may be too high through a possible combination of too high emissions in the CMIP6 inventory and injection of the emissions into the surface layer only.

The sulphur cycle is a key area of analysis and development for UKESM1 given its importance as a driver of historical aerosol forcing. UKESM1 is relatively unique amongst models in CMIP6 in that it has a fully interactive atmospheric chemistry scheme coupled to a two-moment (mass and number) aerosol scheme. Given the complexity of the model's chemistry-aerosol treatment within the ES framework, the model's performance here is encouraging and provides confidence in UKESM1, particularly in regard to capturing the historical trend. However there is always space for improvement and to the more realistic treatment of $\mathrm{SO}_{2}$ dry deposition will therefore be incorporated into the planned release of UKESM1.1. This latest model version will be documented in an forthcoming publication which will also address the impact of the $\mathrm{SO}_{2}$ dry deposition changes on aerosol loading and climate. ing the NEMO and CICE modules for oceans and sea ice, respectively. The UM source code also houses the GLOMAP-Mode and UKCA modules. JULES is the source code for land and terrestrial biogeochemistry components. MEDUSA is the source code for the ocean biogeochemistry. Due to intellectual property rights restrictions, we cannot provide either the source code or documentation papers for the UM or JULES. Obtaining the UM. The Met Office Unified Model is available for use under licence. A number of research organisations and national meteorological services use the UM in collaboration with the Met Office to undertake basic atmospheric process research, produce forecasts, develop the UM code and build and evaluate Earth system models. For further information on how to apply for a licence, see http://www.metoffice.gov.uk/research/modelling-systems/unified-model (last access: 17 March 2021). Obtaining JULES. JULES is available under licence, free of charge. For further information on how to gain permission to use JULES for research purposes, see http://jules1sm.github.io/access_req/JULE_access.html (last access: 17 March 2021). Information about the UKESM1 release and its components and the prerequisites for using it can be found here: http://cms.ncas.ac.uk/wiki/UM/Configurations/UKESM. Briefly, UKESM1 is distributed and 
https://doi.org/10.5194/acp-2021-238

Preprint. Discussion started: 28 April 2021

(c) Author(s) 2021. CC BY 4.0 License.

(c) (1)

run as a Rose suite on the Archer2 and Monsoon computing platforms administered by UK Research Innovation and the Met Office/Natural Environment Research Council, respectively. Rose is a framework for developing and running meteorological applications and is described in more detail here: http://cms.ncas.ac.uk/wiki/RoseCylc.

Data availability. The simulation data used in this study are archived on the Earth System Grid Federation (ESGF) node (https://esgfnode.llnl.gov/projects/cmip6/, last access: 17 March 2021). The model source ID is UKESM1-0-LL for UKESM1. UKESM1 historical simulations are identified by the following variant labels: r1i1p1f2, r2i1p1f2, r8i1p1f2 and r9i1p1f2, (https://doi.org/10.22033/ESGF/CMIP6.6113; Tang (2019)). We acknowledge the use of the CASTNet data base (https://www.epa.gov/castnet, last access: 17 March 2021). Information on the EMEP network can be found in Tørseth et al. (2012). OMI total column SO2 data was obtained from NASA's Goddard Earth Sciences Data and Information Services Center (GES DISC, https://disc.gsfc.nasa.gov/, last access: 17 March 2021).

Author contributions. CGJ, JPM, STT and CH contributed to the conceptualization of this study CGJ and STR developed and tested the code changes for the revised dry deposition parameterization. STR ran the UKESM1 and UKESM1-SO2 historical simulations. CH led the analysis and did the data visualization. RP with support from CL evaluated UKESM1 against the OMI $\mathrm{SO}_{2}$ product. $\mathrm{CH}$ led the preparation of the manuscript, with important text contributions from JPM, CGJ and RP. All co-authors contributed invaluable comments in reviewing and editing the manuscript.

The authors declare that they have no conflict of interest. 


\section{Appendix A: Appendix A}
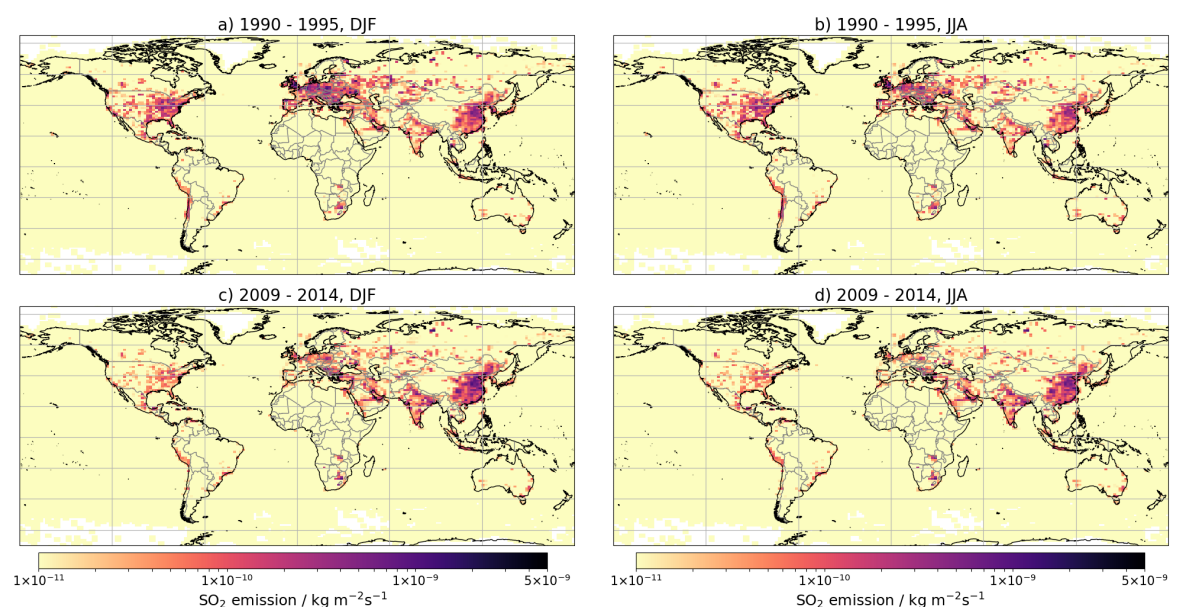

Figure A1. Global emissions of $\mathrm{SO}_{2}$ used in UKESM1. Mean seasonal emissions are shown for the 1990-1995 time slice for DJF (a) and JJA (b), and the 2009-2014 time slice for DJF (c) and JJA (d).

Acknowledgements. For making their measurement data available to be used in this study, we would like to acknowledge the EMEP and CASTNet measurement networks along with any data managers involved in data collection. The EBAS database has largely been funded by the UN-ECE CLRTAP (EMEP), AMAP and through NILU internal resources. Specific developments have been possible due to projects like EUSAAR (EU-FP5)(EBAS web interface), EBAS-Online (Norwegian Research Council INFRA) (upgrading of database platform) and HTAP (European Commission DG-ENV)(import and export routines to build a secondary repository in support of www.htap.org). The US Environmental Protection Agency is the primary funding source for CASTNet, with contracting and research support from the National Park Service. This study used JASMIN, the UK's collaborative data analysis environment (http://jasmin.ac.uk) (Lawrence et al., 2013). CH made extensive use of the Iris and Cartopy libraries for the analysis and data visualisation in this study (Met Office, 2010 - 2013, -).

\section{Financial support.}

This research has been supported by the UK Government, BEIS and DEFRA (grant no. GA01101), the National Environmental Research Council (NERC) National Capability Science Multi-Centre (NCSMC) (UKESM (grant no. NE/N017978/1)). CJ acknowledges funding from the EU Horizon 2020 project CRESCENDO, grant number: 641816. RJP was supported by the UK Natural Environment Research Council (NERC) by providing funding for the National Centre for Earth Observation (NCEO) through grant number NE/R016518/1. STT has been supported by the UK-China Research and Innovation Partnership Fund through the Met Office Climate Science for Service Partnership (CSSP) China as part of the Newton Fund. OMI SO 2 
https://doi.org/10.5194/acp-2021-238

Preprint. Discussion started: 28 April 2021

(c) Author(s) 2021. CC BY 4.0 License.

(c) (i)

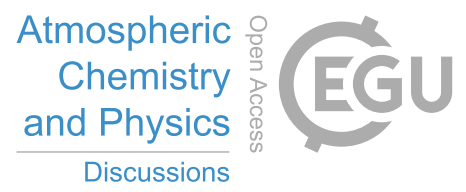

product development and analysis have been supported by NASA Earth Science Division (ESD) Aura Science Team program 775 (Grant \#80NSSC17K0240). 


\section{References}

Aas, W., Mortier, A., Bowersox, V., Cherian, R., Faluvegi, G., Fagerli, H., Hand, J., Klimont, Z., Galy-Lacaux, C., Lehmann, C. M. B., Myhre, C. L., Myhre, G., Olivie, D., Sato, K., Quaas, J., Rao, P. S. P., Schulz, M., Shindell, D., Skeie, R. B., Stein, A., Takemura, T., Tsyro, S., Vet, R., and Xu, X.: Global and regional trends of atmospheric sulfur, SCIENTIFIC REPORTS, 9, https://doi.org/10.1038/s41598-01837304-0, 2019.

Aleksic, N., Roy, K., Sistla, G., Dukett, J., Houck, N., and Casson, P.: Analysis of cloud and precipitation chemistry at Whiteface Mountain, NY, Atmospheric Environment, 43, 2709-2716, 2009.

Altshuller, A.: Model predictions of the rates of homogeneous oxidation of sulfur dioxide to sulfate in the troposphere, Atmospheric Environment (1967), 13, 1653 - 1661, https://doi.org/https://doi.org/10.1016/0004-6981(79)90323-8, http://www.sciencedirect.com/science/ article/pii/0004698179903238, 1979.

Archer-Nicholls, S., Abraham, N. L., Shin, Y. M., Weber, J., Russo, M. R., Lowe, D., Utembe, S., O’Connor, F. M., Kerridge, B., Latter, B., et al.: The Common Representative Intermediates Mechanism version 2 in the United Kingdom Chemistry and Aerosols Model, Earth and Space Science Open Archive ESSOAr, 2020.

Archibald, A. T., O'Connor, F. M., Abraham, N. L., Archer-Nicholls, S., Chipperfield, M. P., Dalvi, M., Folberth, G. A., Dennison, F., Dhomse, S. S., Griffiths, P. T., Hardacre, C., Hewitt, A. J., Hill, R. S., Johnson, C. E., Keeble, J., Köhler, M. O., Morgenstern, O., Mulcahy, J. P., Ordóñez, C., Pope, R. J., Rumbold, S. T., Russo, M. R., Savage, N. H., Sellar, A., Stringer, M., Turnock, S. T., Wild, O., and Zeng, G.: Description and evaluation of the UKCA stratosphere-troposphere chemistry scheme (StratTrop vn 1.0) implemented in UKESM1, Geoscientific Model Development, 13, 1223-1266, https://doi.org/10.5194/gmd-13-1223-2020, https://gmd.copernicus.org/ articles/13/1223/2020/, 2020.

Baumgardner, R., Lavery, T., Rogers, C., and Isil, S.: Estimates of the atmospheric deposition of sulfur and nitrogen species: Clean Air Status and Trends Network, 1990-2000, ENVIRONMENTAL SCIENCE \& TECHNOLOGY, 36, 2614-2629, https://doi.org/10.1021/es011146g, 2002.

Best, M. J., Pryor, M., Clark, D. B., Rooney, G. G., Essery, R. L. H., Ménard, C. B., Edwards, J. M., Hendry, M. A., Porson, A., Gedney, N., Mercado, L. M., Sitch, S., Blyth, E., Boucher, O., Cox, P. M., Grimmond, C. S. B., and Harding, R. J.: The Joint UK Land Environment Simulator (JULES), model description - Part 1: Energy and water fluxes, Geoscientific Model Development, 4, 677-699, https://doi.org/10.5194/gmd-4-677-2011, https://gmd.copernicus.org/articles/4/677/2011/, 2011.

Boucher, O., Randall, D., Artaxo, P., Bretherton, C., Feingold, G., Forster, P., Kerminen, V.-M., Kondo, Y., Liao, H., Lohmann, U., et al.: Clouds and aerosols, in: Climate change 2013: the physical science basis. Contribution of Working Group I to the Fifth Assessment Report of the Intergovernmental Panel on Climate Change, pp. 571-657, Cambridge University Press, 2013.

Chin, M., Rood, R. B., Lin, S.-J., M??ller, J.-F., and Thompson, A. M.: Atmospheric sulfur cycle simulated in the global model GOCART: Model description and global properties, Journal of Geophysical Research: Atmospheres, 105, 24671-24687, https://doi.org/https://doi.org/10.1029/2000JD900384, https://agupubs.onlinelibrary.wiley.com/doi/abs/10.1029/2000JD900384, 2000.

Clark, D. B., Mercado, L. M., Sitch, S., Jones, C. D., Gedney, N., Best, M. J., Pryor, M., Rooney, G. G., Essery, R. L. H., Blyth, E., Boucher, O., Harding, R. J., Huntingford, C., and Cox, P. M.: The Joint UK Land Environment Simulator (JULES), model description Part 2: Carbon fluxes and vegetation dynamics, Geoscientific Model Development, 4, 701-722, https://doi.org/10.5194/gmd-4-701-2011, https://gmd.copernicus.org/articles/4/701/2011/, 2011. 

RONMENT, 31, 3667-3678, https://doi.org/10.1016/S1352-2310(97)00141-6, 1997.

Crippa, M., Guizzardi, D., Muntean, M., Schaaf, E., Dentener, F., van Aardenne, J. A., Monni, S., Doering, U., Olivier, J. G. J., Pagliari, V., and Janssens-Maenhout, G.: Gridded emissions of air pollutants for the period 1970-2012 within EDGAR v4.3.2, EARTH SYSTEM SCIENCE DATA, 10, 1987-2013, https://doi.org/10.5194/essd-10-1987-2018, 2018.

Dentener, F., Kinne, S., Bond, T., Boucher, O., Cofala, J., Generoso, S., Ginoux, P., Gong, S., Hoelzemann, J. J., Ito, A., Marelli, L., Penner, J. E., Putaud, J.-P., Textor, C., Schulz, M., van der Werf, G. R., and Wilson, J.: Emissions of primary aerosol and precursor gases in the years 2000 and 1750 prescribed data-sets for AeroCom, Atmospheric Chemistry and Physics, 6, 4321-4344, https://doi.org/10.5194/acp6-4321-2006, https://acp.copernicus.org/articles/6/4321/2006/, 2006.

Dyer, A.: A review of flux-profile relationships, Boundary-Layer Meteorology, 7, 363-372, 1974.

E. Sickles, II, J. and Shadwick, D. S.: Changes in air quality and atmospheric deposition in the eastern United States: 1990-2004, JOURNAL OF GEOPHYSICAL RESEARCH-ATMOSPHERES, 112, https://doi.org/10.1029/2006JD007843, 2007.

Erisman, J. W. and Baldocchi, D.: Modelling dry deposition of SO2, Tellus B, 46, 159-171, https://doi.org/https://doi.org/10.1034/j.16000889.1994.t01-2-00001.x, https://onlinelibrary.wiley.com/doi/abs/10.1034/j.1600-0889.1994.t01-2-00001.x, 1994.

Erisman, J. W., Pul, A. V., and Wyers, P.: Parametrization of surface resistance for the quantification of atmospheric deposition of acidifying pollutants and ozone, Atmospheric Environment, 28, 2595 - 2607, https://doi.org/https://doi.org/10.1016/1352-2310(94)90433-2, http: //www.sciencedirect.com/science/article/pii/1352231094904332, 1994.

Eyring, V., Bony, S., Meehl, G. A., Senior, C. A., Stevens, B., Stouffer, R. J., and Taylor, K. E.: Overview of the Coupled Model Intercomparison Project Phase 6 (CMIP6) experimental design and organization, GEOSCIENTIFIC MODEL DEVELOPMENT, 9, 1937-1958, https://doi.org/10.5194/gmd-9-1937-2016, 2016.

Feng, L., Smith, S. J., Braun, C., Crippa, M., Gidden, M. J., Hoesly, R., Klimont, Z., van Marle, M., van den Berg, M., and van der Werf, G. R.: The generation of gridded emissions data for CMIP6, Geoscientific Model Development, 13, 461-482, https://doi.org/10.5194/gmd13-461-2020, https://gmd.copernicus.org/articles/13/461/2020/, 2020.

Finkelstein, P., Ellestad, T., Clarke, J., Meyers, T., Schwede, D., Hebert, E., and Neal, J.: Ozone and sulfur dioxide dry deposition to forests: Observations and model evaluation, JOURNAL OF GEOPHYSICAL RESEARCH-ATMOSPHERES, 105, 15365-15377, https://doi.org/10.1029/2000JD900185, 2000.

Fioletov, V. E., McLinden, C. A., Krotkov, N., Li, C., Joiner, J., Theys, N., Carn, S., and Moran, M. D.: A global catalogue of large SO2 sources and emissions derived from the Ozone Monitoring Instrument, Atmospheric Chemistry and Physics, 16, 11497-11 519, https://doi.org/10.5194/acp-16-11497-2016, https://acp.copernicus.org/articles/16/11497/2016/, 2016.

Fowler, D.: DRY DEPOSITION OF SO2 ON AGRICULTURAL CROPS, in: Sulfur in the Atmosphere, edited by HUSAR, R., LODGE, J., and MOORE, D., pp. 369 - 373, Pergamon, https://doi.org/https://doi.org/10.1016/B978-0-08-022932-4.50041-0, http: //www.sciencedirect.com/science/article/pii/B9780080229324500410, 1978.

Fowler, D., Pilegaard, K., Sutton, M. A., Ambus, P., Raivonen, M., Duyzer, J., Simpson, D., Fagerli, H., Fuzzi, S., Schjoerring, J. K., Granier, C., Neftel, A., Isaksen, I. S. A., Laj, P., Maione, M., Monks, P. S., Burkhardt, J., Daemmgen, U., Neirynck, J., Personne, E., Wichink-Kruit, R., Butterbach-Bahl, K., Flechard, C., Tuovinen, J. P., Coyle, M., Gerosa, G., Loubet, B., Altimir, N., Gruenhage, L., Ammann, C., Cieslik, S., Paoletti, E., Mikkelsen, T. N., Ro-Poulsen, H., Cellier, P., Cape, J. N., Horvath, L., Loreto, F., Niinemets, U., Palmer, P. I., Rinne, J., Misztal, P., Nemitz, E., Nilsson, D., Pryor, S., Gallagher, M. W., Vesala, T., Skiba, U., Brueggemann, N., Zechmeister-Boltenstern, S., Williams, J., O’Dowd, C., Facchini, M. C., de Leeuw, G., Flossman, A., Chaumerliac, N., and Eris- 
man, J. W.: Atmospheric composition change: Ecosystems-Atmosphere interactions, ATMOSPHERIC ENVIRONMENT, 43, 5193-5267, https://doi.org/10.1016/j.atmosenv.2009.07.068, 2009.

Garland, J. A. and Branson, J. R.: The deposition of sulphur dioxide to pine forest assessed by a radioactive tracer method, Tellus, 29, 445-454, https://doi.org/https://doi.org/10.1111/j.2153-3490.1977.tb00755.x, https://onlinelibrary.wiley.com/doi/abs/10.1111/j. 2153-3490.1977.tb00755.x, 1977.

Guo, J., Wang, Y., Shen, X., Wang, Z., Lee, T., Wang, X., Li, P., Sun, M., Collett, J. L., Wang, W., and Wang, T.: Characterization of cloud water chemistry at Mount Tai, China: Seasonal variation, anthropogenic impact, and cloud processing, Atmospheric Environment, 60, 467-476, https://doi.org/https://doi.org/10.1016/j.atmosenv.2012.07.016, https://www.sciencedirect.com/science/article/pii/ S1352231012006887, 2012.

Hoesly, R. M., Smith, S. J., Feng, L., Klimont, Z., Janssens-Maenhout, G., Pitkanen, T., Seibert, J. J., Vu, L., Andres, R. J., Bolt, R. M., et al.: Historical (1750-2014) anthropogenic emissions of reactive gases and aerosols from the Community Emission Data System (CEDS), Geoscientific Model Development, 11, 369-408, 2018.

Holland, D. M., Principe, P. P., and Sickles, J. E.: Trends in atmospheric sulfur and nitrogen species in the eastern United States for 19891995, Atmospheric Environment, 33, 37 - 49, https://doi.org/https://doi.org/10.1016/S1352-2310(98)00123-X, http://www.sciencedirect. com/science/article/pii/S135223109800123X, 1998.

Holtslag, A. A. M. and Bruin, H. A. R. D.: Applied Modeling of the Nighttime Surface Energy Balance over Land, Journal of Applied Meteorology and Climatology, 27, 689 - 704, https://doi.org/10.1175/1520-0450(1988)027<0689:AMOTNS>2.0.CO;2, https://journals. ametsoc.org/view/journals/apme/27/6/1520-0450_1988_027_0689_amotns_2_0_co_2.xml, 1988.

Janssens-Maenhout, G., Crippa, M., Guizzardi, D., Dentener, F., Muntean, M., Pouliot, G., Keating, T., Zhang, Q., Kurokawa, J., Wankmueller, R., van der Gon, H. D., Kuenen, J. J. P., Klimont, Z., Frost, G., Darras, S., Koffi, B., and Li, M.: HTAPv2.2: a mosaic of regional and global emission grid maps for 2008 and 2010 to study hemispheric transport of air pollution, ATMOSPHERIC CHEMISTRY AND PHYSICS, 15, 11 411-11 432, https://doi.org/10.5194/acp-15-11411-2015, 2015.

Karset, I. H. H., Berntsen, T. K., Storelvmo, T., Alterskjær, K., Grini, A., Olivié, D., Kirkevåg, A., Seland, Ø., Iversen, T., and Schulz, M.: Strong impacts on aerosol indirect effects from historical oxidant changes, Atmospheric Chemistry and Physics, 18, 7669-7690, https://doi.org/10.5194/acp-18-7669-2018, https://acp.copernicus.org/articles/18/7669/2018/, 2018.

Kipling, Z., Stier, P., Schwarz, J. P., Perring, A. E., Spackman, J. R., Mann, G. W., Johnson, C. E., and Telford, P. J.: Constraints on aerosol processes in climate models from vertically-resolved aircraft observations of black carbon, ATMOSPHERIC CHEMISTRY AND PHYSICS, 13, 5969-5986, https://doi.org/10.5194/acp-13-5969-2013, 2013.

Kreidenweis, S. M., Walcek, C. J., Feingold, G., Gong, W., Jacobson, M. Z., Kim, C.-H., Liu, X., Penner, J. E., Nenes, A., and Seinfeld, J. H.: Modification of aerosol mass and size distribution due to aqueous-phase SO2 oxidation in clouds: Comparisons of several models, Journal of Geophysical Research: Atmospheres, 108, 2003.

Krotkov, N. A., McLinden, C. A., Li, C., Lamsal, L. N., Celarier, E. A., Marchenko, S. V., Swartz, W. H., Bucsela, E. J., Joiner, J., Duncan, B. N., Boersma, K. F., Veefkind, J. P., Levelt, P. F., Fioletov, V. E., Dickerson, R. R., He, H., Lu, Z., and Streets, D. G.: Aura OMI observations of regional SO2 and NO2 pollution changes from 2005 to 2015, Atmospheric Chemistry and Physics, 16, 4605-4629, https://doi.org/10.5194/acp-16-4605-2016, https://acp.copernicus.org/articles/16/4605/2016/, 2016.

Kuhlbrodt, T., Jones, C. G., Sellar, A., Storkey, D., Blockley, E., Stringer, M., Hill, R., Graham, T., Ridley, J., Blaker, A., Calvert, D., Copsey, D., Ellis, R., Hewitt, H., Hyder, P., Ineson, S., Mulcahy, J., Siahaan, A., and Walton, J.: The Low-Resolution Version of HadGEM3 GC3.1: 

https://doi.org/10.1029/2018MS001370, 2018.

Lawrence, B. N., Bennett, V. L., Churchill, J., Juckes, M., Kershaw, P., Pascoe, S., Pepler, S., Pritchard, M., and Stephens, A.: Storing and manipulating environmental big data with JASMIN, in: 2013 IEEE International Conference on Big Data, pp. 68-75, https://doi.org/10.1109/BigData.2013.6691556, 2013.

Lee, C., Martin, R. V., van Donkelaar, A., Lee, H., Dickerson, R. R., Hains, J. C., Krotkov, N., Richter, A., Vinnikov, K., and Schwab, J. J.: SO2 emissions and lifetimes: Estimates from inverse modeling using in situ and global, space-based (SCIAMACHY and OMI) observations, Journal of Geophysical Research: Atmospheres, 116, https://doi.org/https://doi.org/10.1029/2010JD014758, https://agupubs. onlinelibrary.wiley.com/doi/abs/10.1029/2010JD014758, 2011.

Leibensperger, E. M., Mickley, L. J., Jacob, D. J., Chen, W.-T., Seinfeld, J. H., Nenes, A., Adams, P. J., Streets, D. G., Kumar, N., and Rind, D.: Climatic effects of 1950ndash;2050 changes in US anthropogenic aerosols ndash; Part 1: Aerosol trends and radiative forcing, Atmospheric Chemistry and Physics, 12, 3333-3348, https://doi.org/10.5194/acp-12-3333-2012, https://acp.copernicus.org/articles/12/ 3333/2012/, 2012.

Levelt, P. F., Joiner, J., Tamminen, J., Veefkind, J. P., Bhartia, P. K., Stein Zweers, D. C., Duncan, B. N., Streets, D. G., Eskes, H., van der A, R., McLinden, C., Fioletov, V., Carn, S., de Laat, J., DeLand, M., Marchenko, S., McPeters, R., Ziemke, J., Fu, D., Liu, X., Pickering, K., Apituley, A., González Abad, G., Arola, A., Boersma, F., Chan Miller, C., Chance, K., de Graaf, M., Hakkarainen, J., Hassinen, S., Ialongo, I., Kleipool, Q., Krotkov, N., Li, C., Lamsal, L., Newman, P., Nowlan, C., Suleiman, R., Tilstra, L. G., Torres, O., Wang, H., and Wargan, K.: The Ozone Monitoring Instrument: overview of 14 years in space, Atmospheric Chemistry and Physics, 18, 5699-5745, https://doi.org/10.5194/acp-18-5699-2018, https://acp.copernicus.org/articles/18/5699/2018/, 2018.

Li, J., Wang, X., Chen, J., Zhu, C., Li, W., Li, C., Liu, L., Xu, C., Wen, L., Xue, L., Wang, W., Ding, A., and Herrmann, H.: Chemical composition and droplet size distribution of cloud at the summit of Mount Tai, China, Atmospheric Chemistry and Physics, 17, 98859896, https://doi.org/10.5194/acp-17-9885-2017, https://acp.copernicus.org/articles/17/9885/2017/, 2017.

Li, J., Zhu, C., Chen, H., Fu, H., Xiao, H., Wang, X., Herrmann, H., and Chen, J.: A More Important Role for the Ozone-S (IV) Oxidation Pathway Due to Decreasing Acidity in Clouds, Journal of Geophysical Research: Atmospheres, 125, e2020JD033 $220,2020$.

Liu, F., Choi, S., Li, C., Fioletov, V. E., McLinden, C. A., Joiner, J., Krotkov, N. A., Bian, H., Janssens-Maenhout, G., Darmenov, A. S., and da Silva, A. M.: A new global anthropogenic SO2 emission inventory for the last decade: a mosaic of satellite-derived and bottom-up emissions, Atmospheric Chemistry and Physics, 18, 16571-16586, https://doi.org/10.5194/acp-18-16571-2018, https://acp.copernicus. org/articles/18/16571/2018/, 2018.

MACTEC-Engineering and Consulting, I. M.: Clean Air Status and Trends Network (CASTNET) 2004 Annual Report, Tech. rep., Prepared for U. S. Environmental Protection Agency, Research Triangle Park, NC, USA, https://www3.epa.gov/castnet/docs/annual_report_2004. pdf, 2005.

Mann, G. W., Carslaw, K. S., Spracklen, D. V., Ridley, D. A., Manktelow, P. T., Chipperfield, M. P., Pickering, S. J., and Johnson, C. E.: Description and evaluation of GLOMAP-mode: a modal global aerosol microphysics model for the UKCA composition-climate model, GEOSCIENTIFIC MODEL DEVELOPMENT, 3, 519-551, https://doi.org/10.5194/gmd-3-519-2010, 2010.

McHale, M. R., Ludtke, A. S., Wetherbee, G. A., Burns, D. A., Nilles, M. A., and Finkelstein, J. S.: Trends in precipitation chemistry across the U.S. 1985-2017: Quantifying the benefits from 30 years of Clean Air Act amendment regulation, Atmospheric Environment, 247, 118 219, https://doi.org/https://doi.org/10.1016/j.atmosenv.2021.118219, https://www.sciencedirect.com/science/article/ pii/S1352231021000376, 2021. 
Meagher, J. F., Bailey, E. M., and Luria, M.: The seasonal variation of the atmospheric SO2 to SO4 2??? conversion rate, Journal of Geophysical Research: Oceans, 88, 1525-1527, https://doi.org/https://doi.org/10.1029/JC088iC02p01525, https://agupubs.onlinelibrary.wiley.com/ doi/abs/10.1029/JC088iC02p01525, 1983.

Met Office: Iris: A Python package for analysing and visualising meteorological and oceanographic data sets, Exeter, Devon, v1.2 edn., http://scitools.org.uk/, 2010 - 2013.

Met Office: Cartopy: a cartographic python library with a Matplotlib interface, Exeter, Devon, https://scitools.org.uk/cartopy, 2010 - 2015.

Meyers, T. P., Finkelstein, P., Clarke, J., Ellestad, T. G., and Sims, P. F.: A multilayer model for inferring dry deposition using standard meteorological measurements, Journal of Geophysical Research: Atmospheres, 103, 22645-22661, https://doi.org/https://doi.org/10.1029/98JD01564, https://agupubs.onlinelibrary.wiley.com/doi/abs/10.1029/98JD01564, 1998.

Monks, S. A., Arnold, S. R., Hollaway, M. J., Pope, R. J., Wilson, C., Feng, W., Emmerson, K. M., Kerridge, B. J., Latter, B. L., Miles, G. M., Siddans, R., and Chipperfield, M. P.: The TOMCAT global chemical transport model v1.6: description of chemical mechanism and model evaluation, Geoscientific Model Development, 10, 3025-3057, https://doi.org/10.5194/gmd-10-3025-2017, https://gmd.copernicus. org/articles/10/3025/2017/, 2017.

Mulcahy, J., Jones, C., Sellar, A., Johnson, B., Boutle, I., Jones, A., Andrews, T., Rumbold, S., Mollard, J., Bellouin, N., et al.: Improved aerosol processes and effective radiative forcing in HadGEM3 and UKESM1, Journal of Advances in Modeling Earth Systems, 10, 2786$2805,2018$.

Mulcahy, J. P., Johnson, C., Jones, C. G., Povey, A. C., Scott, C. E., Sellar, A., Turnock, S. T., Woodhouse, M. T., Abraham, N. L., Andrews, M. B., Bellouin, N., Browse, J., Carslaw, K. S., Dalvi, M., Folberth, G. A., Glover, M., Grosvenor, D. P., Hardacre, C., Hill, R., Johnson, B., Jones, A., Kipling, Z., Mann, G., Mollard, J., O’Connor, F. M., Palmiéri, J., Reddington, C., Rumbold, S. T., Richardson, M., Schutgens, N. A. J., Stier, P., Stringer, M., Tang, Y., Walton, J., Woodward, S., and Yool, A.: Description and evaluation of aerosol in UKESM1 and HadGEM3-GC3.1 CMIP6 historical simulations, Geoscientific Model Development, 13, 6383-6423, https://doi.org/10.5194/gmd13-6383-2020, https://gmd.copernicus.org/articles/13/6383/2020/, 2020.

Murray, G. L., Kimball, K. D., Hill, L. B., Hislop, J. E., and Weathers, K. C.: Long-term trends in cloud and rain chemistry on Mount Washington, New Hampshire, Water, Air, \& Soil Pollution, 224, 1653, 2013.

O’Connor, F. M., Johnson, C. E., Morgenstern, O., Abraham, N. L., Braesicke, P., Dalvi, M., Folberth, G. A., Sanderson, M. G., Telford, P. J., Voulgarakis, A., Young, P. J., Zeng, G., Collins, W. J., and Pyle, J. A.: Evaluation of the new UKCA climate-composition model Part 2: The Troposphere, GEOSCIENTIFIC MODEL DEVELOPMENT, 7, 41-91, https://doi.org/10.5194/gmd-7-41-2014, 2014.

Paulot, F., Fan, S., and Horowitz, L. W.: Contrasting seasonal responses of sulfate aerosols to declining SO2 emissions in the Eastern U.S.: Implications for the efficacy of SO2 emission controls, Geophysical Research Letters, 44, 455-464, https://doi.org/https://doi.org/10.1002/2016GL070695, https://agupubs.onlinelibrary.wiley.com/doi/abs/10.1002/2016GL070695, 2017.

Payrissat, M. and Beilke, S.: Laboratory measurements of the uptake of sulphur dioxide by different European soils, Atmospheric Environment (1967), 9, 211 - 217, https://doi.org/https://doi.org/10.1016/0004-6981(75)90069-4, http://www.sciencedirect.com/science/article/ pii/0004698175900694, 1975.

Pham, M., Muller, J., Brasseur, G., Granier, C., and Megie, G.: A 3D model study of the global sulphur cycle: Contributions of anthropogenic and biogenic sources, ATMOSPHERIC ENVIRONMENT, 30, 1815-1822, https://doi.org/10.1016/1352-2310(95)00390-8, Joint 8th CACGP/2nd IGAC Conference on Global Atmospheric Chemistry, FUJI, JAPAN, SEP 05-09, 1994, 1996.

Pope, R. J, H. C. L. C. and Chipperfield, M. P.: United Kingdom Earth System Model - Ozone Monitoring Instrument Total Column Sulphur Dioxide Comparisons, Tech. rep., Prepared for U. K. Met Office Hadley Centre, Met Office, Exeter, EX1 3PB, UK, 2021. 
Pope, R. J., Richards, N. A. D., Chipperfield, M. P., Moore, D. P., Monks, S. A., Arnold, S. R., Glatthor, N., Kiefer, M., Breider, T. J., Harrison, J. J., Remedios, J. J., Warneke, C., Roberts, J. M., Diskin, G. S., Huey, L. G., Wisthaler, A., Apel, E. C., Bernath, P. F., and Feng, W.: Intercomparison and evaluation of satellite peroxyacetyl nitrate observations in the upper troposphere-lower stratosphere, Atmospheric Chemistry and Physics, 16, 13 541-13 559, https://doi.org/10.5194/acp-16-13541-2016, https://acp.copernicus.org/articles/ 16/13541/2016/, 2016.

Revell, L. E., Kremser, S., Hartery, S., Harvey, M., Mulcahy, J. P., Williams, J., Morgenstern, O., McDonald, A. J., Varma, V., Bird, L., and Schuddeboom, A.: The sensitivity of Southern Ocean aerosols and cloud microphysics to sea spray and sulfate aerosol production in the HadGEM3-GA7.1 chemistry-climate model, Atmospheric Chemistry and Physics, 19, 15 447-15 466, https://doi.org/10.5194/acp19-15447-2019, https://acp.copernicus.org/articles/19/15447/2019/, 2019.

Ridley, J. K., Blockley, E. W., Keen, A. B., Rae, J. G., West, A. E., and Schroeder, D.: The sea ice model component of HadGEM3-GC3. 1, Geoscientific Model Development, 11, 713-723, 2018.

Sander, S., Friedl, R., Barker, J., Golden, D., Kurylo, M., Wine, P., Abbatt, J., Burkholder, J., Kolb, C., Moortgat, G., et al.: Chemical kinetics and photochemical data for use in atmospheric studies, evaluation number 14, JPL Publ., 02, 25, 334, 2003.

Saylor, R. D., Wolfe, G. M., Meyers, T. P., and Hicks, B. B.: A corrected formulation of the Multilayer Model (MLM) for inferring gaseous dry deposition to vegetated surfaces, Atmospheric Environment, 92, 141 - 145, https://doi.org/https://doi.org/10.1016/j.atmosenv.2014.03.056, http://www.sciencedirect.com/science/article/pii/S1352231014002416, 2014.

Schwab, J. J., Casson, P., Brandt, R., Husain, L., Dutkewicz, V., Wolfe, D., Demerjian, K. L., Civerolo, K. L., Rattigan, O. V., Felton, H. D., and Dukett, J. E.: Atmospheric Chemistry Measurements at Whiteface Mountain, NY: Cloud Water Chemistry, Precipitation Chemistry, and Particulate Matter, AEROSOL AND AIR QUALITY RESEARCH, 16, 841-854, https://doi.org/10.4209/aaqr.2015.05.0344, 2nd Atmospheric Chemistry and Physics at Mountain Sites Symposium, Steamboat Springs, CO, AUG 11-15, $2014,2016$.

Seland, Ø., Bentsen, M., Olivié, D., Toniazzo, T., Gjermundsen, A., Graff, L. S., Debernard, J. B., Gupta, A. K., He, Y.-C., Kirkevåg, A., et al.: Overview of the Norwegian Earth System Model (NorESM2) and key climate response of CMIP6 DECK, historical, and scenario simulations, Geoscientific Model Development, 13, 6165-6200, 2020.

Sellar, A. A., Jones, C. G., Mulcahy, J. P., Tang, Y., Yool, A., Wiltshire, A., O’Connor, F. M., Stringer, M., Hill, R., Palmieri, J., Woodward, S., de Mora, L., Kuhlbrodt, T., Rumbold, S. T., Kelley, I, D., Ellis, R., Johnson, C. E., Walton, J., Abraham, N. L., Andrews, M. B., Andrews, T., Archibald, A. T., Berthou, S., Burke, E., Blockley, E., Carslaw, K., Dalvi, M., Edwards, J., Folberth, G. A., Gedney, N., Griffiths, P. T., Harper, A. B., Hendry, M. A., Hewitt, A. J., Johnson, B., Jones, A., Jones, C. D., Keeble, J., Liddicoat, S., Morgenstern, O., Parker, R. J., Predoi, V., Robertson, E., Siahaan, A., Smith, R. S., Swaminathan, R., Woodhouse, M. T., Zeng, G., and Zerroukat, M.: UKESM1: Description and Evaluation of the UK Earth System Model, JOURNAL OF ADVANCES IN MODELING EARTH SYSTEMS, 11, 4513-4558, https://doi.org/10.1029/2019MS001739, 2019.

Sickles, II, J. E. and Shadwick, D. S.: Seasonal and regional air quality and atmospheric deposition in the eastern United States, JOURNAL OF GEOPHYSICAL RESEARCH-ATMOSPHERES, 112, https://doi.org/10.1029/2006JD008356, 2007.

Sickles II, J. E. and Shadwick, D. S.: Air quality and atmospheric deposition in the eastern US: 20 years of change, Atmospheric Chemistry and Physics, 15, 173-197, https://doi.org/10.5194/acp-15-173-2015, https://acp.copernicus.org/articles/15/173/2015/, 2015.

1000 Smith, F. and Jeffrey, G.: Airborne transport of sulphur dioxide from the U.K., Atmospheric Environment (1967), 9, 643 659, https://doi.org/https://doi.org/10.1016/0004-6981(75)90008-6, http://www.sciencedirect.com/science/article/pii/0004698175900086, 1975. 
Storkey, D., Blaker, A. T., Mathiot, P., Megann, A., Aksenov, Y., Blockley, E. W., Calvert, D., Graham, T., Hewitt, H. T., Hyder, P., et al.: UK Global Ocean GO6 and GO7: A traceable hierarchy of model resolutions, Geoscientific Model Development, 11, 3187-3213, 2018.

Tan, J., Fu, J. S., Dentener, F., Sun, J., Emmons, L., Tilmes, S., Sudo, K., Flemming, J., Jonson, J. E., Gravel, S., Bian, H., Davila, Y., Henze, D. K., Lund, M. T., Kucsera, T., Takemura, T., and Keating, T.: Multi-model study of HTAP II on sulfur and nitrogen deposition, ATMOSPHERIC CHEMISTRY AND PHYSICS, 18, 6847-6866, https://doi.org/10.5194/acp-18-6847-2018, 2018.

Tang, Yongming; Rumbold, S. E. R. K. D. M. J. S. A. W. J. J. C.: MOHC UKESM1.0-LL model output prepared for CMIP6 CMIP historical CMIP historical, Version 20200818, Earth System Grid Federation, https://doi.org/10.22033/ESGF/CMIP6.6113, https://doi.org/10. 22033/ESGF/CMIP6.6113, 2019.

Tang, Y. S., Braban, C. F., Dragosits, U., Simmons, I., Leaver, D., van Dijk, N., Poskitt, J., Thacker, S., Patel, M., Carter, H., Pereira, M. G., Keenan, P. O., Lawlor, A., Conolly, C., Vincent, K., Heal, M. R., and Sutton, M. A.: Acid gases and aerosol measurements in the UK (19992015): regional distributions and trends, ATMOSPHERIC CHEMISTRY AND PHYSICS, 18, 16 293-16 324, https://doi.org/10.5194/acp18-16293-2018, 2018.

Torseth, K., Aas, W., Breivik, K., Fjaeraa, A. M., Fiebig, M., Hjellbrekke, A. G., Myhre, C. L., Solberg, S., and Yttri, K. E.: Introduction to the European Monitoring and Evaluation Programme (EMEP) and observed atmospheric composition change during 1972-2009, ATMOSPHERIC CHEMISTRY AND PHYSICS, 12, 5447-5481, https://doi.org/10.5194/acp-12-5447-2012, 2012.

Turnock, S. T., Mann, G. W., Woodhouse, M. T., Dalvi, M., O’Connor, F. M., Carslaw, K. S., and Spracklen, V, D.: The Impact of Changes in Cloud Water pH on Aerosol Radiative Forcing, GEOPHYSICAL RESEARCH LETTERS, 46, 4039-4048, https://doi.org/10.1029/2019GL082067, 2019.

Turnock, S. T., Spracklen, D. V., Carslaw, K. S., Mann, G. W., Woodhouse, M. T., Forster, P. M., Haywood, J., Johnson, C. E., Dalvi, M., Bellouin, N., and Sanchez-Lorenzo, A.: Modelled and observed changes in aerosols and surface solar radiation over Europe between 1960 and 2009, ATMOSPHERIC CHEMISTRY AND PHYSICS, 15, 9477-9500, https://doi.org/10.5194/acp-15-9477-2015, 2015.

Ukhov, A., Mostamandi, S., da Silva, A., Flemming, J., Alshehri, Y., Shevchenko, I., and Stenchikov, G.: Assessment of natural and anthropogenic aerosol air pollution in the Middle East using MERRA-2, CAMS data assimilation products, and high-resolution WRFChem model simulations, Atmospheric Chemistry and Physics, 20, 9281-9310, https://doi.org/10.5194/acp-20-9281-2020, https://acp. copernicus.org/articles/20/9281/2020/, 2020.

van Marle, M. J. E., Kloster, S., Magi, B. I., Marlon, J. R., Daniau, A.-L., Field, R. D., Arneth, A., Forrest, M., Hantson, S., Kehrwald, N. M., Knorr, W., Lasslop, G., Li, F., Mangeon, S., Yue, C., Kaiser, J. W., and van der Werf, G. R.: Historic global biomass burning emissions for CMIP6 (BB4CMIP) based on merging satellite observations with proxies and fire models (1750-2015), Geoscientific Model Development, 10, 3329-3357, https://doi.org/10.5194/gmd-10-3329-2017, https://gmd.copernicus.org/articles/10/3329/2017/, 2017.

VanCuren, R. T. and Gustin, M. S.: Identification of sources contributing to PM2.5 and ozone at elevated sites in the western U.S. by receptor analysis: Lassen Volcanic National Park, California, and Great Basin National Park, Nevada, Science of The Total Environment, 530-531, 505-518, https://doi.org/https://doi.org/10.1016/j.scitotenv.2015.03.091, https://www.sciencedirect.com/science/article/ pii/S0048969715003666, 2015.

Vet, R., Artz, R. S., Carou, S., Shaw, M., Ro, C.-U., Aas, W., Baker, A., Bowersox, V. C., Dentener, F., Galy-Lacaux, C., Hou, A., Pienaar, J. J., Gillett, R., Cristina Forti, M., Gromov, S., Hara, H., Khodzher, T., Mahowald, N. M., Nickovic, S., Rao, P. S. P., and Reid, N. W.: A global assessment of precipitation chemistry and deposition of sulfur, nitrogen, sea salt, base cations, organic acids, acidity and pH, and phosphorus, ATMOSPHERIC ENVIRONMENT, 93, 3-100, https://doi.org/10.1016/j.atmosenv.2013.10.060, 2014. 
Walters, D., Baran, A. J., Boutle, I., Brooks, M., Earnshaw, P., Edwards, J., Furtado, K., Hill, P., Lock, A., Manners, J., et al.: The Met Office Unified Model global atmosphere 7.0/7.1 and JULES global land 7.0 configurations, Geoscientific Model Development, 12, 1909-1963, 2019.

Wang, Z., Xie, F., Sakurai, T., Ueda, H., Han, Z., Carmichael, G., Streets, D., Engardt, M., Holloway, T., Hayami, H., Kajino, M., Thongboonchoo, N., Bennet, C., Park, S., Fung, C., Chang, A., Sartelet, K., and Amann, M.: MICS-Asia II: Model inter-comparison and evaluation of acid deposition, Atmospheric Environment, 42, 3528-3542, https://doi.org/https://doi.org/10.1016/j.atmosenv.2007.12.071, https://www.sciencedirect.com/science/article/pii/S1352231008000101, mICS-ASIA II, 2008.

Wesely, M.: Parameterization of surface resistances to gaseous dry deposition in regional-scale numerical-models, Atmospheric Environment, 23, 1293-1304, https://doi.org/10.1016/0004-6981(89)90153-4, 1989.

Williams, K. D., Copsey, D., Blockley, E. W., Bodas-Salcedo, A., Calvert, D., Comer, R., Davis, P., Graham, T., Hewitt, H. T., Hill, R., Hyder, P., Ineson, S., Johns, T. C., Keen, A. B., Lee, R. W., Megann, A., Milton, S. F., Rae, J. G. L., Roberts, M. J., Scaife, A. A., Schiemann, R., Storkey, D., Thorpe, L., Watterson, I. G., Walters, D. N., West, A., Wood, R. A., Woollings, T., and Xavier, P. K.: The Met Office Global Coupled Model 3.0 and 3.1 (GC3.0 and GC3.1) Configurations, JOURNAL OF ADVANCES IN MODELING EARTH SYSTEMS, 10, 357-380, https://doi.org/10.1002/2017MS001115, 2018.

Wu, T., Zhang, F., Zhang, J., Jie, W., Zhang, Y., Wu, F., Li, L., Yan, J., Liu, X., Lu, X., Tan, H., Zhang, L., Wang, J., and Hu, A.: Beijing Climate Center Earth System Model version 1 (BCC-ESM1): model description and evaluation of aerosol simulations, Geoscientific Model Development, 13, 977-1005, https://doi.org/10.5194/gmd-13-977-2020, 2020.

Wys, J. N. D., Hill, A., and Robinson, E.: Assessment of the fate of Sulphur Dioxide from a point source, in: Sulfur in the Atmosphere, edited by HUSAR, R., LODGE, J., and MOORE, D., pp. 633 - 639, Pergamon, https://doi.org/https://doi.org/10.1016/B978-0-08-0229324.50065-3, http://www.sciencedirect.com/science/article/pii/B9780080229324500653, 1978.

Yang, Y., Smith, S. J., Wang, H., Lou, S., and Rasch, P. J.: Impact of Anthropogenic Emission Injection Height Uncertainty on Global Sulfur Dioxide and Aerosol Distribution, JOURNAL OF GEOPHYSICAL RESEARCH-ATMOSPHERES, 124, 4812-4826, https://doi.org/10.1029/2018JD030001, 2019.

Yool, A., Palmi??ri, J., Jones, C. G., Sellar, A. A., de Mora, L., Kuhlbrodt, T., Popova, E. E., Mulcahy, J. P., Wiltshire, A., Rumbold, S. T., Stringer, M., Hill, R. S. R., Tang, Y., Walton, J., Blaker, A., Nurser, A. J. G., Coward, A. C., Hirschi, J., Woodward, S., Kelley, D. I., Ellis, R., and Rumbold-Jones, S.: Spin-up of UK Earth System Model 1 (UKESM1) for CMIP6, Journal of Advances in Modeling Earth Systems, 12, e2019MS001 933, https://doi.org/https://doi.org/10.1029/2019MS001933, https://agupubs.onlinelibrary.wiley.com/doi/abs/ 10.1029/2019MS001933, e2019MS001933 10.1029/2019MS001933, 2020.

Yool, A., Popova, E. E., and Anderson, T. R.: MEDUSA-2.0: an intermediate complexity biogeochemical model of the marine carbon cycle for climate change and ocean acidification studies, GEOSCIENTIFIC MODEL DEVELOPMENT, 6, 1767-1811, https://doi.org/10.5194/gmd-6-1767-2013, 2013.

Zhang, L., Brook, J., and Vet, R.: A revised parameterization for gaseous dry deposition in air-quality models, ATMOSPHERIC CHEMISTRY AND PHYSICS, 3, 2067-2082, https://doi.org/10.5194/acp-3-2067-2003, 2003.

Zhao, B., Jiang, J. H., Gu, Y., Diner, D., Worden, J., Liou, K.-N., Su, H., Xing, J., Garay, M., and Huang, L.: Decadal-scale trends in regional aerosol particle properties and their linkage to emission changes, Environmental Research Letters, 12, 054021, https://doi.org/10.1088/1748-9326/aa6cb2, https://doi.org/10.1088/1748-9326/aa6cb2, 2017. 
https://doi.org/10.5194/acp-2021-238

Preprint. Discussion started: 28 April 2021

(c) Author(s) 2021. CC BY 4.0 License.

(c) (i)

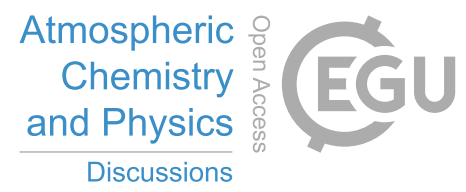

Zheng, B., Tong, D., Li, M., Liu, F., Hong, C., Geng, G., Li, H., Li, X., Peng, L., Qi, J., Yan, L., Zhang, Y., Zhao, H., Zheng, Y., He, K., and Zhang, Q.: Trends in China's anthropogenic emissions since 2010 as the consequence of clean air actions, Atmospheric Chemistry and Physics, 18, 14 095-14 111, https://doi.org/10.5194/acp-18-14095-2018, https://acp.copernicus.org/articles/18/14095/2018/, 2018. 